\title{
A Method to Diagnose, Improve, and Evaluate Children's Learning Using Wearable Devices Such as Mobile Devices in the IoT Environment
}

\author{
Mohammad Moradi (iD) and Kheirollah Rahsepar Fard \\ Computer Engineering and Information Technology, University of Qom, Qom, Iran \\ Correspondence should be addressed to Mohammad Moradi; mohammad.moradi@alumni.ut.ac.ir
}

Received 16 August 2020; Revised 30 September 2020; Accepted 21 October 2020; Published 30 October 2020

Academic Editor: Ondrej Krejcar

Copyright (c) 2020 Mohammad Moradi and Kheirollah Rahsepar Fard. This is an open access article distributed under the Creative Commons Attribution License, which permits unrestricted use, distribution, and reproduction in any medium, provided the original work is properly cited.

\begin{abstract}
Every day we see an increasing tendency to use technology in education. In recent years, the impact of technology on the education process has received much attention. One of the important effects of technology is that it increases children's motivation and selfconfidence and increases group collaboration. The purpose of this paper is to transform the traditional classroom into a modern classroom in order to increase the ease and efficiency of the teaching process. The method includes phases of diagnosis and improvement. In the diagnose phase, the classroom is equipped with modern items such as Internet of Things (IoT) and gamebased learning. In the improvement phase, the field method is used to extract and weight the effective criteria in improving the educational status. The proposed method has been tested on two English language kindergartens. The children tested were in the age group of 8 to 10 years. In the implementation of the proposed educational method in the first English language kindergarten, the average improvement of education and learning of children has almost doubled, which has been maintained by doubling the number of children tested in the implementation of the proposed educational method in the second English language kindergarten. As a result, the proposed educational method can increase the learning performance of children.
\end{abstract}

\section{Introduction}

Childhood is one of the influential periods in human life. Childhood has a great impact on adulthood. During this time, the foundation of a healthy and prosperous life can be laid and many future problems can be prevented. Therefore, attention to children is essential [1-5]. Education is one of the basic principles of life. In the world, a person cannot be found not owing his or her basic and sophisticated performance to learning. Education is a set of decisions and actions that are taken to achieve specific goals $[6,7]$. The importance of childhood education is in two aspects: one is the children's effectiveness and the other the profound effects of learning during this period. There is a relationship between intellectual growth and initial experiences of children. Benjamin Bloom believes that about $50 \%$ of the growth of intelligence is from birth to age 4, about $30 \%$ between ages 4 and 8 , and the remaining 20\% between 8 and 17 years of age, which shows to pay special attention to childhood [8]. Therefore, addressing the issue of the child, especially the aspect of child education, is very necessary.

We live in a modern world of technology where technology directly or indirectly affects the daily life of every person. Research has shown that technology can enhance children's learning $[9,10]$. There are several reasons for using technology in teaching and learning [11]:

(1) One of the main reasons is that learners are interested in using technology and feel comfortable with these devices. They are more interested in using technology to learn.

(2) The technology employs four components of learning: active participation, teamwork, frequent feedback, and interaction with real-world experts. 
(3) Provides learners with professional opportunities.

(4) Technology has made it easier for teachers. They can specify course materials, submit automated online quizzes, and save time. Class management is easier and more efficient.

(5) Technology provides an opportunity beyond the classroom. Learners can use the resources available on the Internet.

(6) This technology helps learners do their homework using online systems. They can browse lesson videos and view other related resources.

(7) This helps save resources and money. Technology can make teachers more efficient.

The purpose of this study is to transform the traditional classroom into a modern classroom in order to increase the ease and efficiency of the teaching process and thus improve children's learning performance. To this end, the classroom is equipped with IoT and game-based learning. These types of classes are implemented as an element of the IoT in the learning process instead of traditional learning. The method involves three phases of diagnosis, improvement, and evaluation. The questions of this research include the following:

(1) Can using IoT in game-based learning increase children's motivation and learning rate?

(2) Is it possible to extract and analyze children's communication and education network using IoT in game-based learning?

(3) Do IoT and game-based learning scenarios increase cooperation and communication between children in the learning process?

(4) Can the criteria presented based on each child's situation lead to an improvement in the learning process?

In the continuation of this paper, the items used in the proposed educational method, including IoT, selective dissemination of information (SDI), multiple attribute decision-making (MADM) such as interpretive structural modeling (ISM) and analytical hierarchy process (AHP), complex networks, centrality measures, and game-based learning, are briefly explained. In the next section, related works and their challenges are described. Then, the proposed educational method of training will be discussed with three phases of diagnosis, improvement, and evaluation. Then, the proposed method of teaching children is implemented and tested on a number of children, and the results are presented. Finally, the conclusions are explained.

\section{Theoretical Framework}

In this section, the items used in the proposed educational method, including IoT, SDI, MADM, complex networks, centrality measures, and game-based learning, are briefly described.
2.1. IoT. IoT is one of the new technologies that can help in information gathering and management. It was the term coined by Ashton in 1999. In IoT, other entities besides humans can connect to the Internet. Entities and objects will be able to automatically communicate and exchange needed data [12]. With IoT, all objects are interconnected that can be controlled and managed with the help of apps [13]. In fact, IoT is a new concept in the world of technology and communications that, as a modern technology, enables the transmission of data over communication networks for anything [14-16]. IoT has many applications in various fields and sciences, including education, smart city, smart farming, transportation, health, and energy [17-19]. In this study, objects are items such as educational cards and smartphones that children use to create connections between objects based on the communication and education they have. Figure 1 shows an example of the use of IoT in this study on the subject of child education. According to Figure 1, the objects are educational cards, smartphones, and laptops. During the educational game, children scan the educational cards using a smartphone, and the information from the educational game is sent to the laptop. According to the information obtained, the educator manages the children in order to improve their educational status.

Another example is the study of de la Guía. He has introduced a game in the study of e-books for children in the IoT environment. Puppet characters have been used to motivate children to read the book. Objects are smartphones and puppet characters. By bringing his/her favorite character closer to the smartphone, in each part of the story of the book, the child can determine the continuation of the story with his/her favorite character. As shown in Figure 2, fictional characters can be defined on objects such as toys (with an NFC chip) or other NFC cards such as a subway card.

As another example, Figure 3 shows a child interacting with an owl robot in the IoT environment to enhance language skills. The objects used are owl robots and shapes (prints or three-dimensional objects). The child hears the name of the shape as he/she approaches it to the owl robot. This helps the child to learn language skills.

2.2. Game-Based Learning. The game is an activity that the child does willingly. The reason for this is it arises from inner tendencies. When done, it makes the child happy. Here are some important features to consider:

(i) The game is innate.

(ii) The game depends on the needs, talents, and abilities of the player.

(iii) Playing is a physical, mental, and verbal activity with imagination, thinking, and imitation.

(iv) The game is fun and entertaining.

According to these characteristics, play is not only a matter of wasting excess energy, wasting time, and preventing congestion but also has many important effects on the well-being of children and the development of children's thinking, imagination, accuracy, and creativity [22]. 


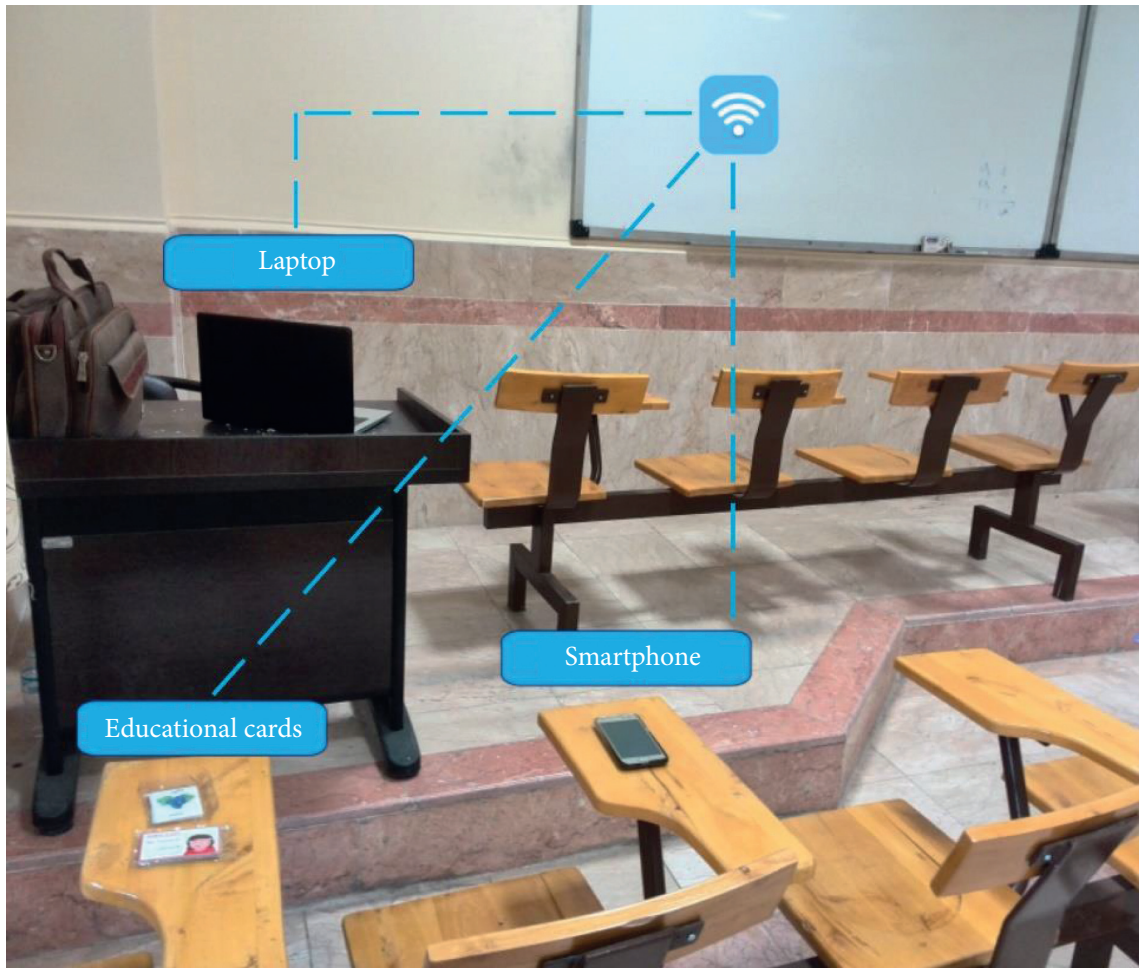

Figure 1: An example of the use of IoT in this study on child education.

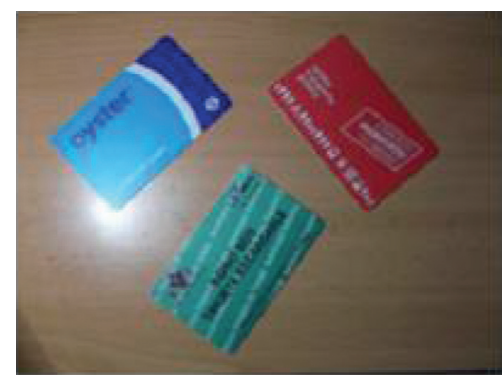

(a)

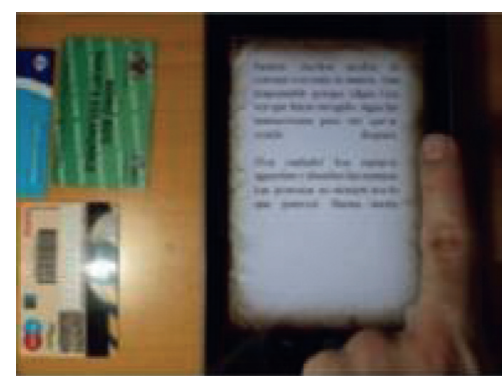

(d)

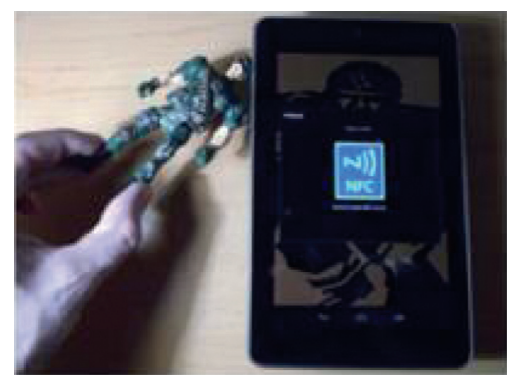

(b)

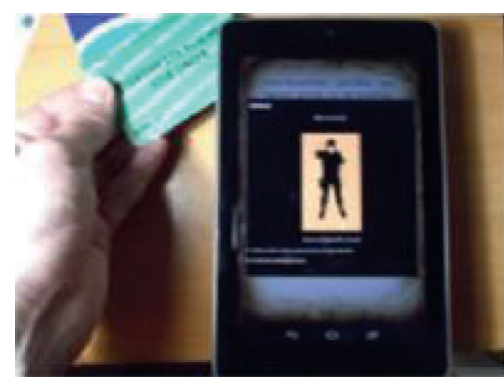

(e)

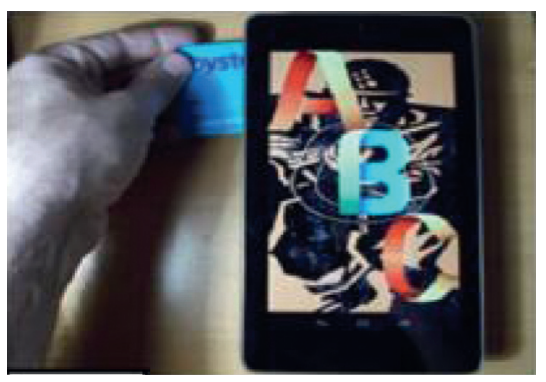

(c)

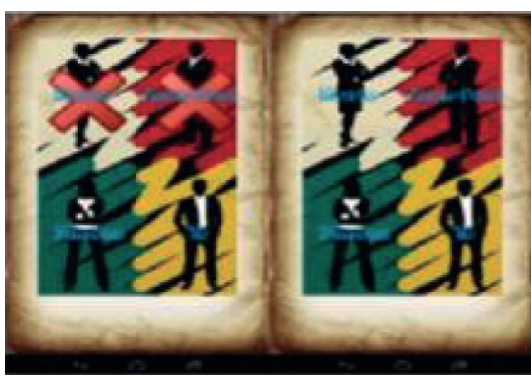

(f)

Figure 2: An example of presenting a game in the study of e-books for children in the IoT environment [20].

One of the most popular teaching methods is gamebased learning. Game-based training is an educational game that uses game elements to learn a specific skill or reach a specific output [23]. Educational games are suggested to increase motivation and thereby improve learning processes [24]. The motivational psychology involved in game-based learning allows students to engage with educational materials in a playful and dynamic way. Gamebased learning is not just creating games for students to play, it is designing learning activities that can incrementally introduce concepts and guide users towards an end goal [25]. 


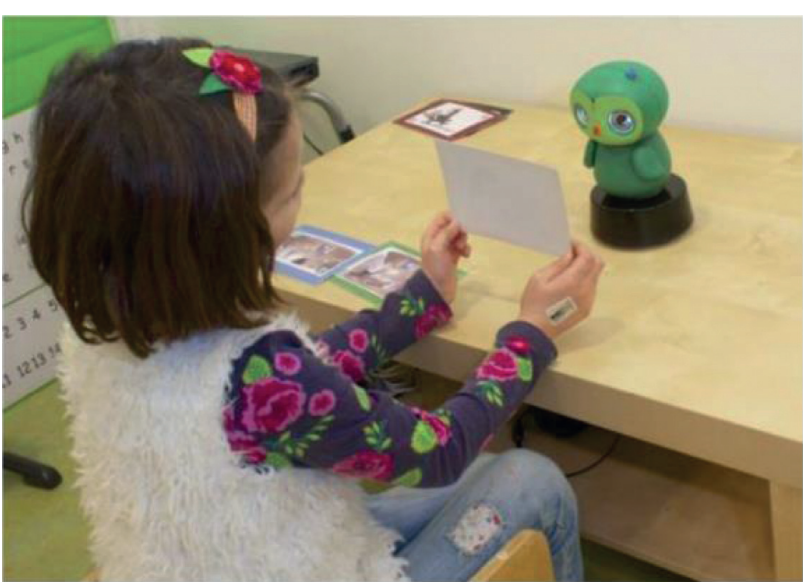

Figure 3: An example of a child interacting with an owl robot to enhance language skills in the IoT environment [21].

2.3. SDI. SDI is a form of presenting and transmitting information, using the search, and sending information required by each user individually, regularly, and continuously [26]. Users identify topics of interest, and new information related to each user's interest is sent separately. The field of new information is usually characterized by words and terms. This is usually done regularly and at specified intervals. In general, the purpose of SDI is to provide, organize, select, and disseminate information to individuals and organizations on a regular basis according to their predetermined needs. The SDI system always keeps a person informed of new developments in his or her field. The SDI system is an information service and an information item, but it is not like a newspaper or magazine to provide everyone with the same information and equality. The list of information for each individual is distinct and personalized. Whatever is sent to anyone depends on their interests and needs. Understanding the interests and needs of users and providing relevant, up-to-date, and timely information to meet their needs are the requirements of information dissemination [27]. O'Neil provides two main reasons for addressing information services [28]:

(1) Increasing information: information is growing exponentially, and users' time to search for their needs and interests is very limited. The information service solves this problem.

(2) Increasing specialization in all disciplines of knowledge leads to information on a subject being available from multiple sources. Information in a source may also be sporadic. The information service helps to capture and aggregate them into a single form.

SDI input is keywords. In this study and in the discussion of education, the key words are the educational status of children.

2.4. MADM. MADM techniques are widely used in many different fields. The reason for this is the ability and capability of these methods to model real issues and make them simple and understandable for most users. In making these decisions, several criteria may be used instead of one. MADM has a variety of decision-making techniques [29]. In this study, attributes are effective criteria in improving the learning and educational status of children.

2.4.1. AHP. One of the most efficient decision-making techniques is the AHP first introduced by Thomas L. Saaty in 1980. This technique was proposed for modeling the decision process, based on pairwise comparisons, allowing managers to examine different scenarios. AHP can be applied to a variety of industrial, commercial, financial, and political applications, and so on [29]. AHP has also been used in education. Anggrainingsih, for example, uses AHP to determine the success factor of e-learning in higher education based on the user's perspective [30]. Effective criteria in improving children's educational and learning status are weighed through AHP to identify criteria with higher priority.

2.4.2. ISM. ISM analyzes the relationship between the criteria at several different levels. ISM is able to determine the relationship between criteria that are individually or ingroup interdependent. The ISM technique steps are identifying the variables related to the problem, filling out the questionnaire and forming the structural self-interaction matrix (SSIM), forming the primary reachability matrix, forming the final reachability matrix, surface segmentation, modeling, penetration power analysis, and the degree of dependency [29]. The ISM technique is used to identify which criteria in the education process can be effective in improving other criteria.

2.5. Complex Networks and Centrality Measures. A complex network is a set of entities (nodes) that are interconnected. Complex network analysis is one of the most useful items in examining the relationships between entities [31]. Centrality measures are one of the most important metrics in analyzing complex networks. Centrality is the descriptive characteristic of actors or groups of actors with multiple structural and parametric determinants for understanding and analyzing their roles in complex networks [32]. Centrality measures are often used to identify powerful, influential, or important actors [33]. The most widely accepted definition of centrality was introduced by Freeman in the late 1970s. Because of their location, they have better access to information and a better opportunity to spread information. In general, centrality is a concept used for network analysis and has different types. Depending on the purpose and definition of the problem, one or more centrality is used. The greater the centrality of an entity, the higher the rank, the more the communication, and the more favorable the position. The centrality measures of different networks are based on several indicators, the most important of which are degree centrality, closeness centrality, betweenness centrality, page rank centrality, and so on. Studying the structure of networks can help you make better decisions. In this study, 
complex networks and centrality measures have been used to identify each child's educational status and which children can be effective in improving the process of educating other children.

2.5.1. Degree Centrality. The degree centrality measure is one of the network metrics or indicators that is useful in analyzing the network structure and positions of entities (nodes) in the network. The degree centrality refers to the number of connections a node has in a network [34]. This measure is related to the position of the nodes in a network and is the number of direct relationships a node has to the network. The degree centrality for each node in the network is measured by counting the number of connections that a node has in the network. In a network graph in this study, nodes are children and links are relationships between children, and degree centrality is calculated by counting the number of connections each child has with other children. The node with the highest degree is the central node in the degree centrality measure [35]. Actors who have a higher centrality have more opportunities and positions than other actors. The absolute degree centrality of the node $v_{i}$ is obtained by the following formula [36]:

$$
c_{D}(i)=\text { degree of vertex } i \text {. }
$$

The relative degree centrality of node $v_{i}$ can be calculated by the following formula:

$$
C_{D}(i)=\frac{c_{D}(i)}{n-1}
$$

where $n-1$ is the largest possible degree of a network with $n$ nodes.

2.5.2. Closeness Centrality. In some cases, those nodes may be of interest, located close to the other nodes of the network. These nodes disseminate information in fewer steps on the network. This type of centrality is called closeness centrality. The closeness centrality of node $v_{i}$ can be calculated by the following formula [36]:

$$
C_{i}=\frac{n}{\sum_{j} d_{i j}}
$$

where $n$ is the number of network nodes and $d_{i j}$ is the shortest distance between node $v_{i}$ and node $v_{j}$.

\section{Related Works}

In this section, research and related works done in the use of modern technologies to enhance the child's learning (by increasing the motivation of the child to learn and increase the ease of learning of the child) are discussed. The purpose of this section is to examine the research conducted on the use of technology in the educational process in order to identify the scientific gap that exists in this field.

Abdi and Cavus have created an affordable, sustainable, and safe educational toy for prekindergarten children between the ages of 4 and 5 for teaching English language as a second language in developing countries. This toy is made with Raspberry Pi and uses RFID technology [37].

Higgins et al. explore the impact of digital technologies on children's learning. The purpose of this study is to provide some evidence on the impact of digital technologies on academic achievement. The purpose of this study is to identify the future investment implications of using digital technology for learning in schools [38].

Safar et al. discuss the effectiveness of using augmented reality applications as a teaching and learning item when instructing kindergarten children the English alphabet in the State of Kuwait. The study concludes with relevant proposals and recommendations regarding the implementation of $A R$ technology in education [39].

Sadiq et al. created an educational application that can be run on a mobile phone based on the principles of user interface design using voice recognition engines to convert text into speech, which will help children learn English language [40].

Uzelac et al. have extracted the parameters that influence students' focus during lectures using IoT. The main purpose is to identify the parameters that significantly influence the students' focus of lectures. Several parameters have been measured in a real classroom environment using inexpensive smart devices. The study is based on data collected from 14 lectures attended by 197 students. After the experiments, 5 parameters that had significant effect were finally extracted [41].

Manches et al. have designed three questions about IoT and children. Research shows how digitizing objects such as toys can influence children's attitudes and behavior and thus educate children and affect children's daily activities [42].

Zhamanov et al. combine IoT with gaming. They state that it is difficult today to motivate students with traditional ways. In this article, the authors examine the classroom equipped with modern items such as IoT and gaming. They implement these types of classes as an element of IoT for the learning process rather than traditional learning. The authors compare the IoT-equipped classroom with the traditional methods. The results show that the modern classroom method is better than the traditional classroom with a difference of approximately $20 \%$ increase in average attendance, laboratory work, tests, midterm exams, and final exams [43].

Spyrou et al. use IoT in the game. A learning goal is set, and the way to achieve it is divided into several tasks, called learning atoms, that are realized as serious games. The user impact status is constantly monitored by devices such as cameras and microphones. A learning goal, for example, counting, is considered. The learning goal is broken down into several learning atoms. For example, in the learning objective of counting, it is divided into learning atoms larger or smaller in numbers, and so on. Then, a learning game is designed for each of the learning atoms. The level of the game is commensurate with the level of learning and user status [44].

Tangworakitthaworn et al. deal with the game-based learning system for plant monitoring based on IoT technology. A new approach, synchronization between the three 
main components of real plant care, game-based learning, and IoT technology, is discussed. A game-based learning system has been introduced, and empirical investigations of satisfaction with the use of suggested games in practical use have been reported. The innovation of this proposed game is that players must complete the level of play by taking care of the actual plant. There are three key components, namely, game-based learning, plant monitoring, and IoT technology, that work together to achieve game results [45].

de la Guía et al. present an e-book for children. Doll characters have been used to increase children's motivation to read books. By approaching each of their favorite characters in each part of the story, the children can determine the continuation of the story with their favorite character [20].

$\mathrm{Li}$ et al. examine the use of games to teach serious subjects such as math to 7- to 8-year-old children. In this study, an exploratory experiment is reported to examine how the various interaction techniques (digital screen-touch interaction vs. real-world tangible interaction) and the different feedback mechanisms in mathematics education for children are affected. Results show that diegetic feedback led to the game being considered significantly more enjoyable, as well as inducing greater feelings of competence and autonomy; screen-touch interaction versus tangible interaction did not change motivation directly nor did find interaction effects between the presentation and interaction modes. After analyzing the results, recommendations for increasing the motivation of serious games for children are suggested [46].

de la Guía et al. explore the impact of using IoT to help teachers strengthen social and classroom interactions. IoTbased systems have been developed to improve motivation, collaboration, and learning in schools. The system is made up of three main components: the home screen (user interface), which shows training tasks, activity, feedback, results, and so on; the wearable device; and the smart object commonly used by NFC sensors. Also, in order to work with the system for teaching English language, according to a word that appeared on the home screen, students would have to search for the relevant object right around the classroom and place it near the wearable device to select it. However, it is difficult for the teacher to control the classroom. To improve the use of this system, new functions and data for teachers have been provided to a web application. The teacher can interact with the system and students through a platform (smartphone, tablet, and laptop). Based on student behavior, the teacher can immediately send a message to control, increase participation and motivation, and encourage cooperation among students. 40 students aged 9-12 years, and 5 teachers participated in the study. The study was conducted in two Spanish classrooms. The results were very positive. $100 \%$ of students responded positively to messages sent by teachers [47].

López-Faican and Jaen evaluate the use of mobile-based multiplayer games for primary school children. A game scenario that can be used to improve communication skills and emotional intelligence in children is evaluated. In this research, two applications of this type of games are considered: (1) competition against the common game; (2) game using mobile technology that creates a geographical scenario with unlimited physical space. The results show that both modes of play create positive emotions such as enthusiasm, pleasure, and curiosity in children. In addition, it has been observed that joint play has a greater impact on emotional affection, social interaction, and interest. In addition, it was observed that the quality of communication in the participatory mode is good in terms of various factors such as maintaining mutual understanding, dialogue management, information collection, reaching consensus, time management, and interaction. In this study, several methods have been proposed in the design of game time management, competitive and participatory modes, dynamic 3D content, and active learning [26]. The table in Appendix summarizes the relevant research based on the researchers' names, year of publication, brief description, and results.

In the following, the challenges of related works as well as proposed solutions to the challenges are presented as the output of this research:

(i) Boring educational methods have been used in most related works to educate the child. In childhood, the most important interests of children are games, which the child does with a tendency and lack of boredom. The proposed educational method is to use games (which are appealing to children) to teach them.

(ii) In related works, effective criteria for children's education have not been extracted, and the education of children has been taken into account regardless of the criteria that affect them which was not the expected performance. In the proposed educational method, it is attempted to extract and measure the criteria influencing children's education and the importance of each criterion through MADM techniques.

(iii) Individual education is usually used in related works and children's pedagogy, and using other children to motivate and learn from each other is not intended, which is the case in the proposed educational method.

(iv) In related works, the child communication network and the issue of networking (learning by using influential children in the network or the so-called charismatic to increase motivation) and the level of education of other children have not been addressed. In the proposed educational method, this issue will be addressed by using complex networks and centrality measures.

(v) Given the high volume of information and the difficulty in selecting the right information, the necessary solutions and communication with parents and child caregivers are not considered. This has been considered using SDI in the proposed method.

\section{Research Methodology}

Today, it is difficult to motivate students with traditional methods. The purpose of this paper is to transform the 
traditional classroom into a modern classroom in order to increase the ease and efficiency of the teaching process and thus improve children's learning performance. The method includes phases of diagnosis and improvement. In the diagnose phase, the classroom is equipped with modern items such as IoT and game-based learning. These types of classes are implemented as an element of the IoT in the learning process instead of traditional learning. In the improvement phase, the field method is used to extract and weight the effective criteria in improving the educational status. The techniques used are AHP and ISM. The data collection tool in this phase is a questionnaire from experts. The proposed method has been tested on two English language kindergartens. The number of participants in the first English language kindergarten is 3 children, and the number of participants in the second English language kindergarten is 6 children. The children tested were in the age group of 8 to 10 years.

\section{Proposed Educational Method}

In this section, the proposed educational method, which includes three phases of child status diagnosis, improvement, and evaluation, is described. In order to increase the attractiveness of the educational process for children, an educational game is provided. The IoT has been used to extract communication networks and training from educational games. Centrality measures have been used to analyze networks and identify children's educational status in the phase of recognizing the proposed educational method. In the phase of improving the educational situation of children, MADM techniques have been used. SDI has been used to inform about the child's status, provide solutions, and communicate with the child's parents.

5.1. Proposed Educational Game. In this section, the steps of the proposed game in the IoT environment are presented. The steps of the proposed game are as follows:

(1) The division of educational materials into $n$ sections (where $n$ is the number of children).

(2) The allocation of each educational section for a child.

(3) The division of each of the $n$ sections into $m$ components to make it easier for the child to learn.

(4) Teaching the assigned section of each child to him/ her by the instructor.

(5) Two types of cards are provided for each child with the following details:

(a) Identification card: this card contains the child's details such as the child's name. Behind the cards, there is the NFC tag or the child's own QR code.

(b) Educational card: the child-assigned section, divided into $m$ components, is written on educational cards with pictures (to enhance visual style). There are $m$ different cards of this type. For example, in English language teaching, educational materials can be animal vocabulary. These words are divided into $n$ sections where $n$ is the number of children. In the example mentioned, the sections can be aquatic animals, insects, and so on. Then, each section is divided into $m$ components. For example, the insect section is divided into the words "ant" and "bee," which are written on the educational cards along with the image. Behind the cards, there is the NFC tag or the child's own QR code.

(6) Children are asked to come together and teach educational cards in accordance with the following rules:

(a) When child $i$ refers to child $j$, child $i$ gives the child identification card to child $j$ and child $j$ after scanning the NFC tag or QR code (by NFC reader or QR code reader that can be an NFCequipped smart bracelet or smartphone reader or QR code) returns it to child $i$.

(b) Then, child $i$ teaches the educational cards to child $j$.

(c) If teaching is successful, child $i$ will give that card to child $j$ and child $j$ will return it to child $i$ after scanning the NFC tag or QR code.

(7) After a specified time, the game ends.

(8) After the game is over, the educational materials and cards listed on each child's training list are tested to determine if the child has learned them correctly. If a child has not been successful, that educational card will be removed from the list of successful trainings.

(9) Children receive scores based on the number of successful training taught to other children and the number of training that has been successfully learned.

Figure 4 shows how to divide educational materials into sections and components and assign them to children (steps 1 to 5 of suggested play).

Through the sixth step of the game, a multilayer network is formed. One layer is the children's communication network with each other and the other is the children's education network with each other. The nodes in both layers are children. The links in the communication network represent the communication of the children, and in the education network, the children teach each other. The rules for forming networks are as follows:

(i) Whenever child $i$ refers to child $j$ for teaching, a directed link from child $i$ to child $j$ is drawn on the communication network. Children's references to each other can be detected by scanning the NFC tag or QR code on each child's identification card.

(ii) Whenever child $i$ successfully teaches child $j$, a directional link from child $i$ to the child trained, i.e., child $j$, is drawn to the education network.

(iii) When a child learns several trainings from another child or teaches several trainings to another child, 


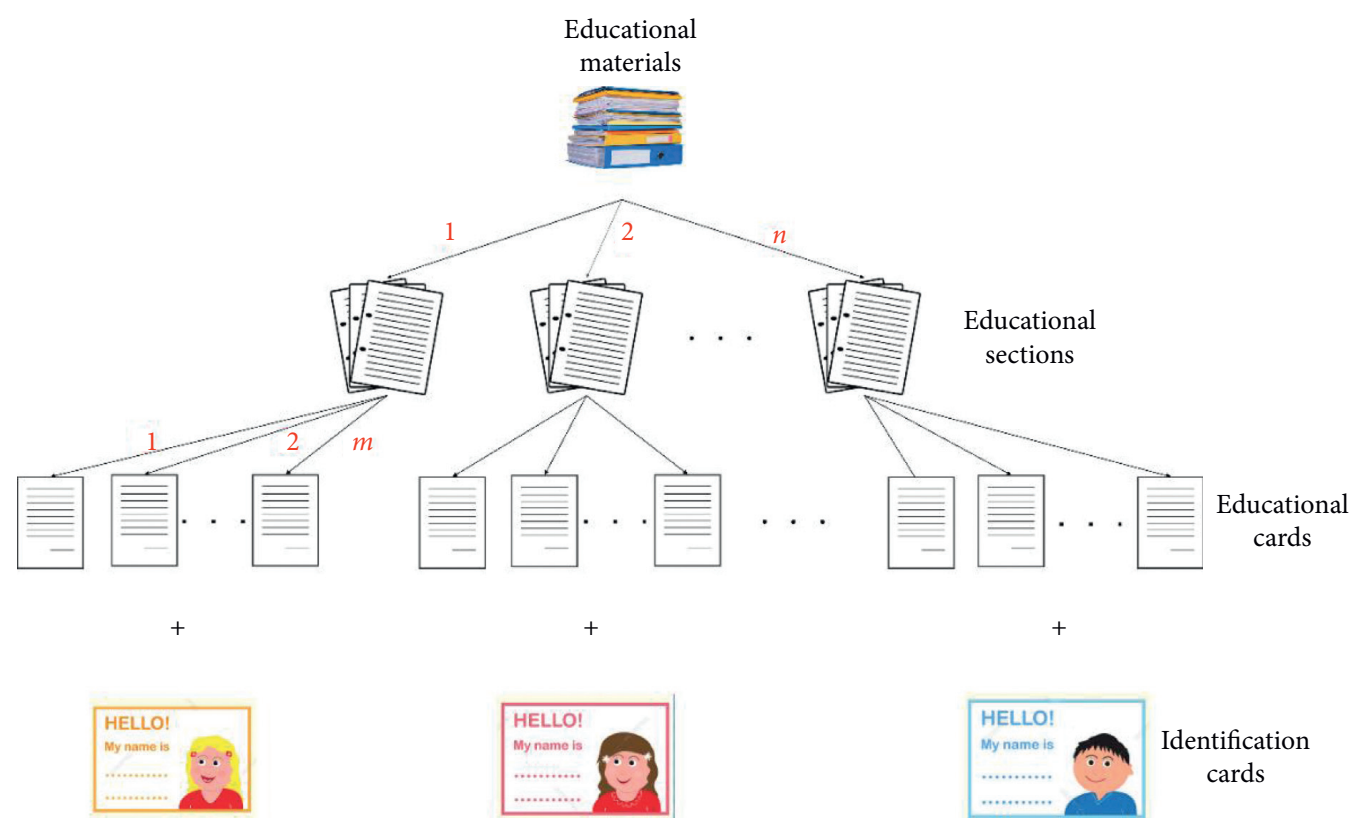

FIGURE 4: Dividing educational materials into educational sections and cards.

the education network link will receive weight on the number of trainings.

(iv) Children are free to choose who to teach or from whom to learn.

Figure 5 shows an example of the layers of the communication and education networks from the proposed training game. The nodes in both networks are children, and the education network links are a subset of the communication network links.

5.2. The Technical Part of IoT in the Proposed Method. As mentioned in the previous section, two types of introduction cards and training cards have been prepared for the educational game. To implement the IoT system, the cards are equipped with the NFC or QR code. Smart bracelets or smartphones equipped with an NFC reader or QR reader code are used for scanning. Figure 6 shows the technical components of the IoT system for extracting the communication network and the education network from the educational game.

As shown in Figure 6, NFC or QR code and wearable devices for scanning them are the main components of the IoT system used in the proposed game. Near-field communication (NFC) is a set of standards in portable devices that allows you to establish peer-to-peer radio communication, which results in the exchange of data by putting them together or pasting them together. NFC is a means of transmitting data over radio waves. From this point of view, it is similar to WiFi and Bluetooth, but it is much faster than Bluetooth and connects two devices by creating an electrical circuit. The NFC data exchange frequency is $13.566 \mathrm{MHz}$. NFC has evolved from radio frequency identification (RFID) and is compatible with most high-frequency RFID-related standards. However, NFC is designed to be used only at close range to prevent RFID from being turned on remotely.
Quick response code (QR) is a square code. Unlike NFC, QR codes do not have any electrical components or do not require special hardware technology. QR codes are the only type of black and white code printed on paper that can be scanned and decrypted using wearable devices such as smartphones.

Wearable devices can be defined as a technology that uses devices that can be placed on the human body. Wearable technologies can be in the form of a smart bracelet, watch, shoes, shirt, hat, necklace, glasses, and more. These smart devices have sensors that collect raw data and can analyze the collected data.

5.3. The Diagnostic Phase of the Child's Status. In this section, the status of children is diagnosed based on the analysis of the communication network and education network from the educational game. Complex network analysis and centrality measures are used to identify important network nodes (which are children) and to divide children into different categories. The following labels can be considered based on the analysis of the communication network:

(i) High input communications: these nodes which have a high input degree of the communication network are actually children who have been referred to by a large number of educators. Other children have a great deal of interest in communicating with these children. These children are called charismatic.

(ii) Low input communications: nodes that have a low input degree centrality in the communication network. In fact, there are very few children who go to train them. These children may be malicious or lack good social interaction and may not be interested in other children. 


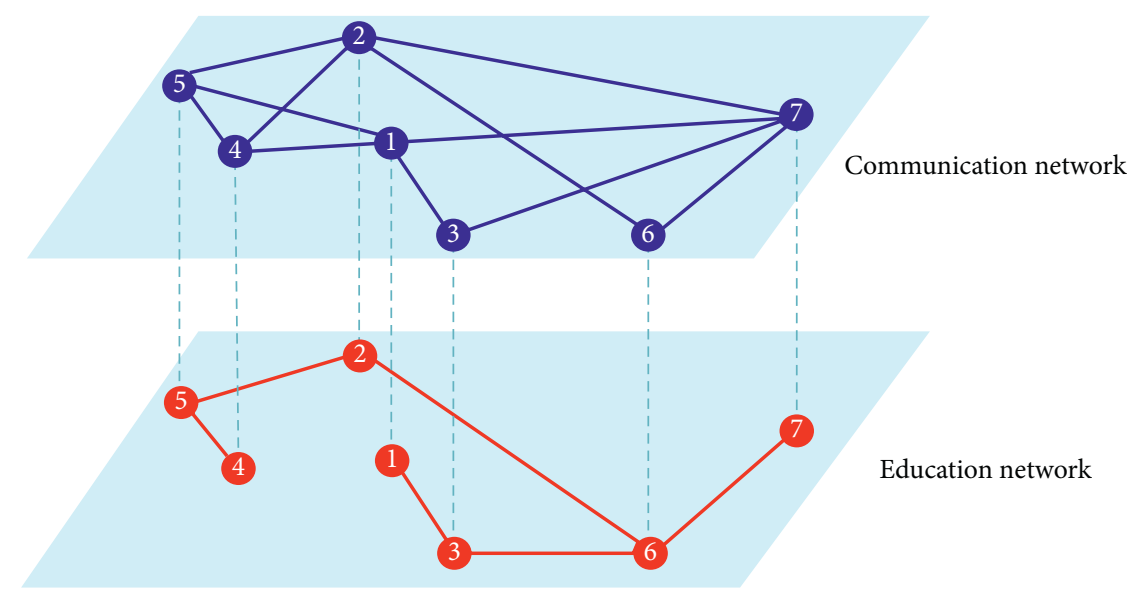

FIGURE 5: An example of a multilayer network consisting of the proposed training game.

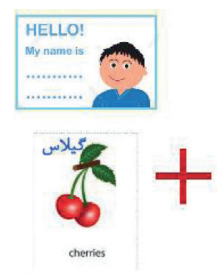

Identification and educational cards

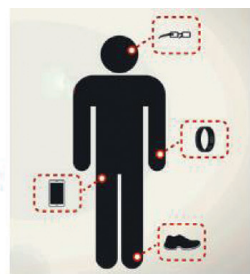

Wearable devices

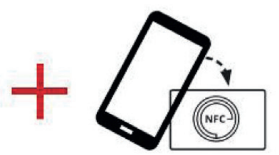

Tap NFC enabled

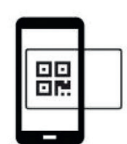

Scan QR code

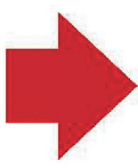

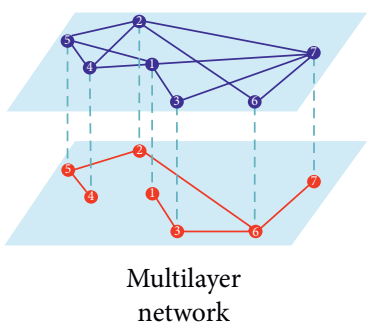

Multilayer
network

Figure 6: Technical components of the IoT system for extracting the communication network and the education network from the educational game.

(iii) High output communications: nodes that have a high output degree centrality in the communications network. In fact, children who have gone to many children for teaching. These children communicate well with almost all children.

(iv) Low output communications: nodes that have a low output degree centrality in the communications network. In fact, children who have trouble communicating with other children.

The following labels can also be considered based on the education network analysis:

(i) High teaching: nodes that have a high output degree centrality in the education network. In fact, children who have been able to teach many children successfully. These children have a great ability to educate and consider the criteria of education.

(ii) Low teaching: nodes with low output degree centrality in the education network. In fact, children who have failed to teach other children well. Two states are possible for this case. Children had low output communication and therefore no teaching or the children had no low output communication but were not successful in teaching. This can be diagnosed by examining other categories in which the child is placed.

(iii) High learning: nodes that have a high input degree centrality. In fact, children who have been able to successfully learn from other children. (iv) Low learning: nodes that have low input degree centrality. There are two possible cases for this. Children had low input communication in the communication network and consequently low learning occurred or the children had no low input communication but were not successful in learning.

Categories can be defined based on the combination of labels (both labels on the same network and labels on two different networks). Here are some of the most important categories:

(1) High output communications, high teaching: these children have both referred to many children for teaching and have been successful in their teaching.

(2) High output communication, low teaching: these children although have referred to many children for teaching have not been successful in teaching.

(3) High input communications, high learning: many of the children have referred to teach them and they have been successful in the learning process.

(4) High input communications, low learning: although many have referred to teach these children, they have had low learning. This shows that regardless of the educator and the type of education the learning of these children is low. For example, they may have low focus and accuracy. 
(5) Low output communications, high input communications: although many have come to teach these children, they have found it difficult to communicate with other children to teach their educational cards.

(6) Low output communications, low input communications: these children have had difficulty communicating with other children whether for teaching or learning.

(7) High output communications, high input communications: these children have been successful in social interaction and communication.

(8) High output communications, low input communications: these children had no difficulty in communicating with other children for education, but other children were reluctant to communicate and educate.

(9) High teaching, high learning: these children have been successful in both teaching and learning.

(10) High teaching, low learning: these children were good educators but not good learners.

(11) Low teaching, high learning: these children were not good educators, but they were good learners.

(12) Low teaching, low learning: these children have been neither successful in teaching nor learning.

(13) Low output communications, low teaching: these children have had difficulty in communicating with other children for teaching, so they have failed in teaching.

(14) Low input communications, low learning: because few children have come to teach these children, little has been learned.

Each child can be into one or more categories, which can be used to determine the final status of the child based on the categories of the child. For example, in the category of "low teaching, low learning," these children may have difficulty in communicating and therefore no education. If these children are also in the category of "low output communication, low input communication," this is true. Also, considering other centrality such as closeness centrality in the communication network, we can diagnose children who are able to teach and disseminate information and educational materials on the network more quickly and give them educational sections that must be taught quickly.

5.4. Improvement Phase. This section outlines the strategies needed to improve the child education process. In the following, the solutions are expressed according to labels and categories.

5.4.1. Categories including "High Teaching". If we want to teach a particular educational section to most children, it is best to give it to these children. Because these children interact with many children and are successful in teaching.
5.4.2. Categories including "High Input Communications". These children are charismatic because many tend to go to them. Therefore, it is important to consider which other categories these children fall into. If they were in the category of "low output communication" or "low teaching," communication and teaching of these children should be strengthened in order to educate a wide range of children. How to improve teaching is described in detail in Section 5.4.4.

5.4.3. Categories including "Low Output Communications" or "Low Input Communications". These children's communication skills need to be strengthened so they can learn or teach educational materials.

5.4.4. Categories including "Low Teaching". This section deals with the improvement of children in the categories including "low teaching." The following can also be applied to the early process of instructor-to-child teaching (teaching of the educational section allocated to the child by the instructor). By studying articles, books, and queries from experts, child teaching criteria were extracted. Criteria of the child teaching process are as follows:

(1) Morality and respect

(2) Providing motivation and interest for learning

(3) Mastering the subject of teaching

(4) Patience

(5) Ability to transfer essential content

(6) Appearance decoration

(7) Using modern teaching tools and methods

(8) General knowledge of educational materials

(9) Assessment based on educational purpose

(10) Learner participation

(11) Learner satisfaction from the teacher

(12) The form and structure of the educational content

(13) Being objective

(14) In-game training

(15) Discipline

Then, a questionnaire was designed to find the effective criteria, and experts were asked to determine the importance of each of the criterion in the child teaching process. In designing the questionnaire, linguistic variables were used which were converted into five-scale Likert. It should be noted that Cronbach's alpha coefficient for the questionnaires of the importance of child teaching criteria was 0.788 which confirms its reliability. According to the experts' opinion, the criteria above the weighted average were selected as the effective criteria as shown in Figure 7.

Next, we used the ISM technique to investigate which criteria may underlie other criteria and to investigate the influence and dependence. Figure 8 shows the levels of effectiveness criteria extracted in the child teaching process based on the ISM technique. 


\begin{tabular}{|c|c|c|c|c|c|c|c|c|c|}
\hline & & & & & \multicolumn{5}{|c|}{ Teaching process } \\
\hline $\begin{array}{l}\text { Morality } \\
\text { and } \\
\text { respect }\end{array}$ & \begin{tabular}{|c|} 
Providing \\
motivation \\
and interest \\
for learning
\end{tabular} & $\left|\begin{array}{c}\text { In-game } \\
\text { training }\end{array}\right|$ & $\begin{array}{l}\text { Mastering } \\
\text { the subject } \\
\text { of teaching }\end{array}$ & Patience & $\begin{array}{c}\text { Being } \\
\text { objective }\end{array}$ & $\begin{array}{c}\text { General } \\
\text { knowledge of } \\
\text { educational } \\
\text { materials }\end{array}$ & $\begin{array}{c}\text { Assessment } \\
\text { based on } \\
\text { educational } \\
\text { purpose }\end{array}$ & $\begin{array}{c}\text { Learner } \\
\text { participation }\end{array}$ & $\begin{array}{c}\text { Learner } \\
\text { satisfaction } \\
\text { from the } \\
\text { teacher }\end{array}$ \\
\hline
\end{tabular}

Figure 7: Hierarchical chart of effective criteria in the child teaching process.

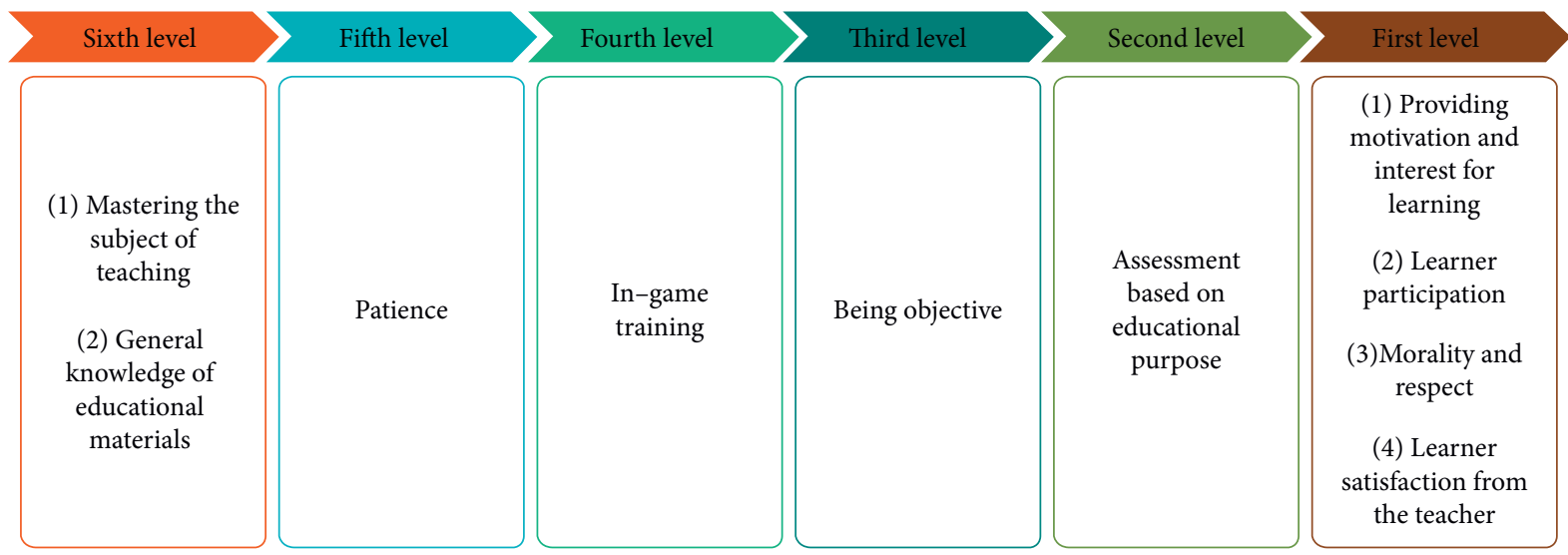

FIGURE 8: Levels of effective criteria extracted in the child teaching process based on the ISM technique.

Figure 9 shows the MICMAC diagram of effective criteria of the child teaching process in the ISM model based on the degree of dependency and influence.

The AHP technique was used to weight the effective indicators extracted in the child teaching process. Table 1 and Figure 10 show the weight and priority of the criteria. It should be noted that the inconsistency rate was 0.02301 which confirms the reliability of the AHP questionnaires because it is less than 0.1 .

As it can be seen from Table 1 and Figure 10, "in-game training" has been ranked first for the child teaching process. The next rankings are "providing motivation and interest for learning," "mastering the subject of teaching," "morality and respect," "being objective," "learner participation," "general knowledge of educational materials," "learner satisfaction from the teacher," "patience," and "assessment based on educational purpose."

5.4.5. Categories including "Low Learning". This section deals with the improvement of children in the categories including "low learning." The following can also be applied to the early process of instructor-to-child education. By studying articles, books, and queries from experts, child learning criteria were extracted. Criteria of a child's learning process include the following:

(1) Preparation and health of body and mind

(2) Purpose and motivation

(3) Past experiences

(4) Learning environment (a) Acoustic and thermal relaxation, use of nature, open spaces, and so on.

(b) Class arrangement (color and light)

(6) Practice

(7) Attention and focus

(8) Discipline

(9) Pay attention to learning style

(10) Intelligence

(a) Hormones

(b) Nutrition

(11) Bonus and rewards

(12) Parental participation

(13) Organization of contents

(14) Find the main theme of each topic

Then, a questionnaire was designed to find effective criteria, and experts were asked to determine the importance of each criterion in the child's learning process. In designing the questionnaire, linguistic variables were used which were converted into five-scale Likert. It should be noted that Cronbach's alpha coefficient for the questionnaires of the importance of child learning criteria was 0.724 which confirms its reliability. According to the experts' opinion, the criteria above the weighted average were selected as the effective criteria as shown in Figure 11.

Next, we used the ISM technique to investigate which criteria may underlie other criteria and to investigate the degree of influence and dependence. Figure 12 shows the 


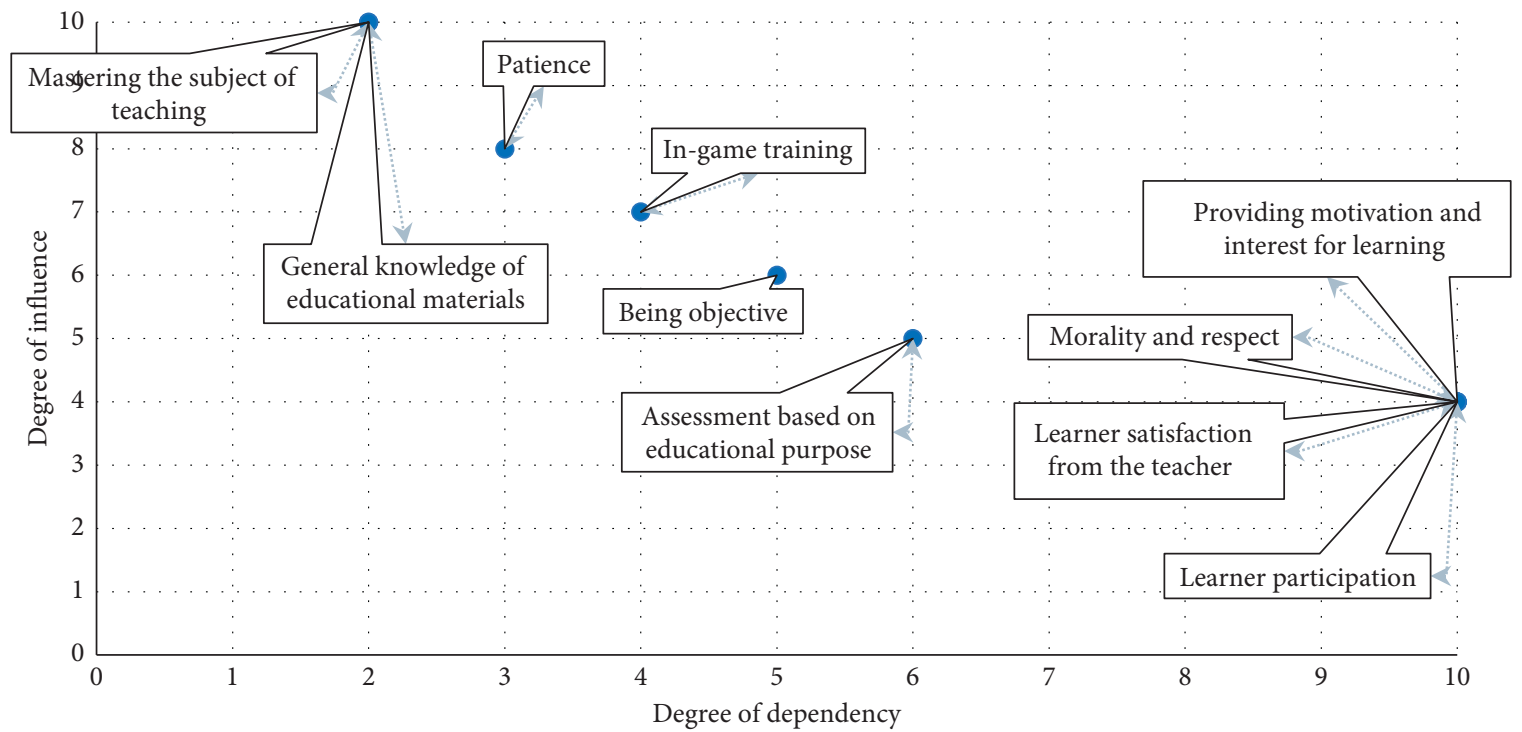

FIGURE 9: MICMAC diagram of effective criteria of the child teaching process in the ISM model.

TABLe 1: Weight and priority of effective criteria extracted in child teaching process based on the AHP technique.

\begin{tabular}{lcc}
\hline Priority & Criterion name & Criterion weight \\
\hline 1 & In-game training & $0 / 18439$ \\
2 & Providing motivation and interest for learning & $0 / 13472$ \\
3 & Mastering the subject of teaching & $0 / 12615$ \\
4 & Morality and respect & $0 / 09784$ \\
5 & Being objective & $0 / 08697$ \\
6 & Learner participation & $0 / 08481$ \\
7 & General knowledge of educational materials & $0 / 08183$ \\
8 & Learner satisfaction from the teacher & $0 / 07968$ \\
9 & Patience & $0 / 0732$ \\
10 & Assessment based on educational purpose & $0 / 0504$ \\
\hline
\end{tabular}

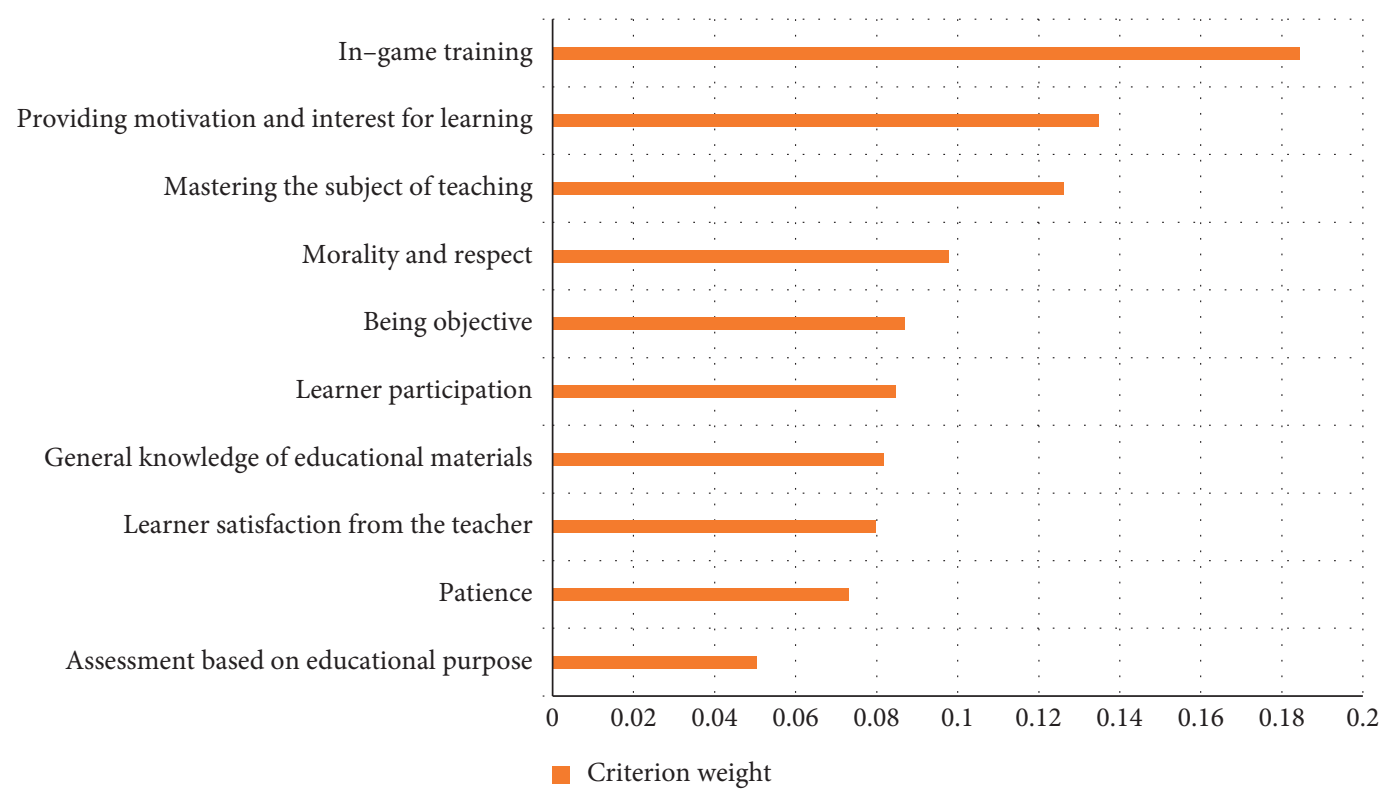

FIgURE 10: Weight chart of the effective criteria extracted in the child teaching process based on the AHP technique. 


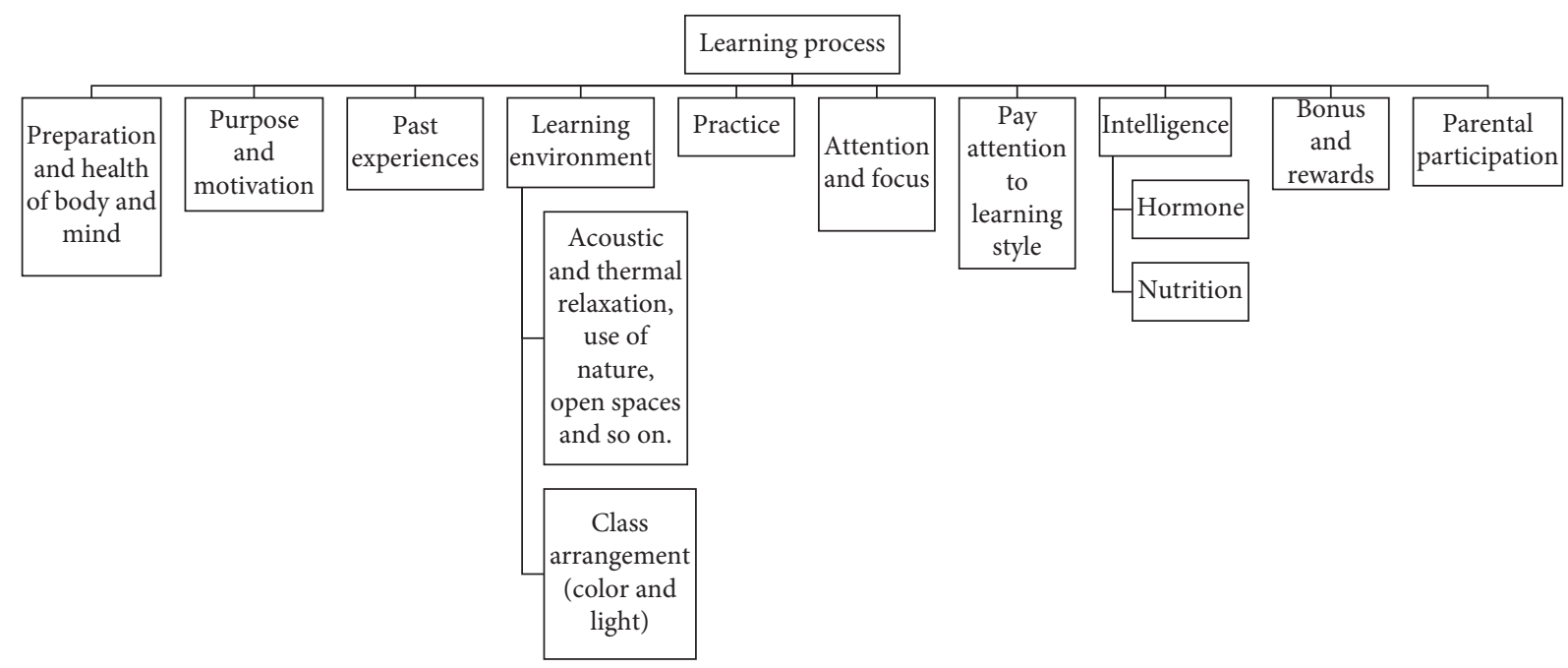

FIgURE 11: Hierarchical chart of effective criteria in the child's learning process.

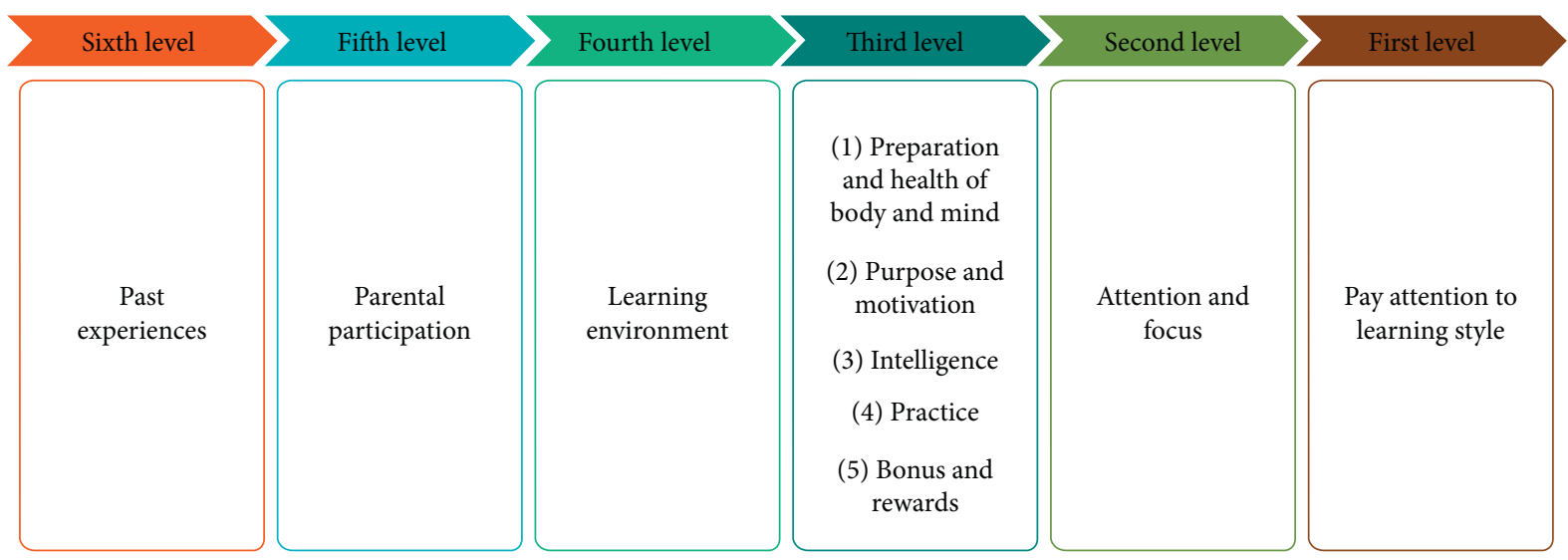

FIGURE 12: Levels of effective criteria extracted in the child learning process based on the ISM technique.

levels of effectiveness criteria extracted in the child learning process based on the ISM technique.

Figure 13 shows the MICMAC diagram of the effective criteria of the child's learning process in the ISM model based on the degree of dependency and influence.

The AHP technique was used to weight the effective criteria extracted in the child's learning process. Table 2 and Figure 14 show the weight and priority of the criteria. It should be noted that the inconsistency rate was 0.0229 which confirms the reliability of the AHP questionnaires because it is less than 0.1 .

As it can be seen from Table 2 and Figure 14, for the child's learning process, the "purpose and motivation" has been ranked first. The next rankings are "practice," "preparation and health of body and mind," "attention and focus," "intelligence," "parental participation," "learning environment," "pay attention to learning styles," "past experiences," and "bonus and rewards." Also, based on the "learning environment" criterion, the subcriterion "acoustic and thermal relaxation, use of nature, open spaces, and so on" with a weight of 0.564 ranked first, and the subcriterion "class arrangement (color and light)" with a weight of 0.436 ranks second.

5.4.6. Children with High Closeness Centrality in the Communication Network. These children are able to teach and disseminate information and educational materials more quickly on the network, so that materials that must be taught quickly can be allocated to them for teaching.

5.4.7. Using SDI System. One of the things that can help improve the education process for children is the use of SDI. In the SDI system, required documents and content are entered as keywords, and the system notifies the user of the matching documents using keywords and matching functions. Therefore, depending on what labels the child receives and in which category, the keywords to improve the child's educational performance can be selected and entered into the SDI system. In addition to the guidelines outlined in this study to improve the child's educational process, articles, books, etc., related to the child labels and category, will be 


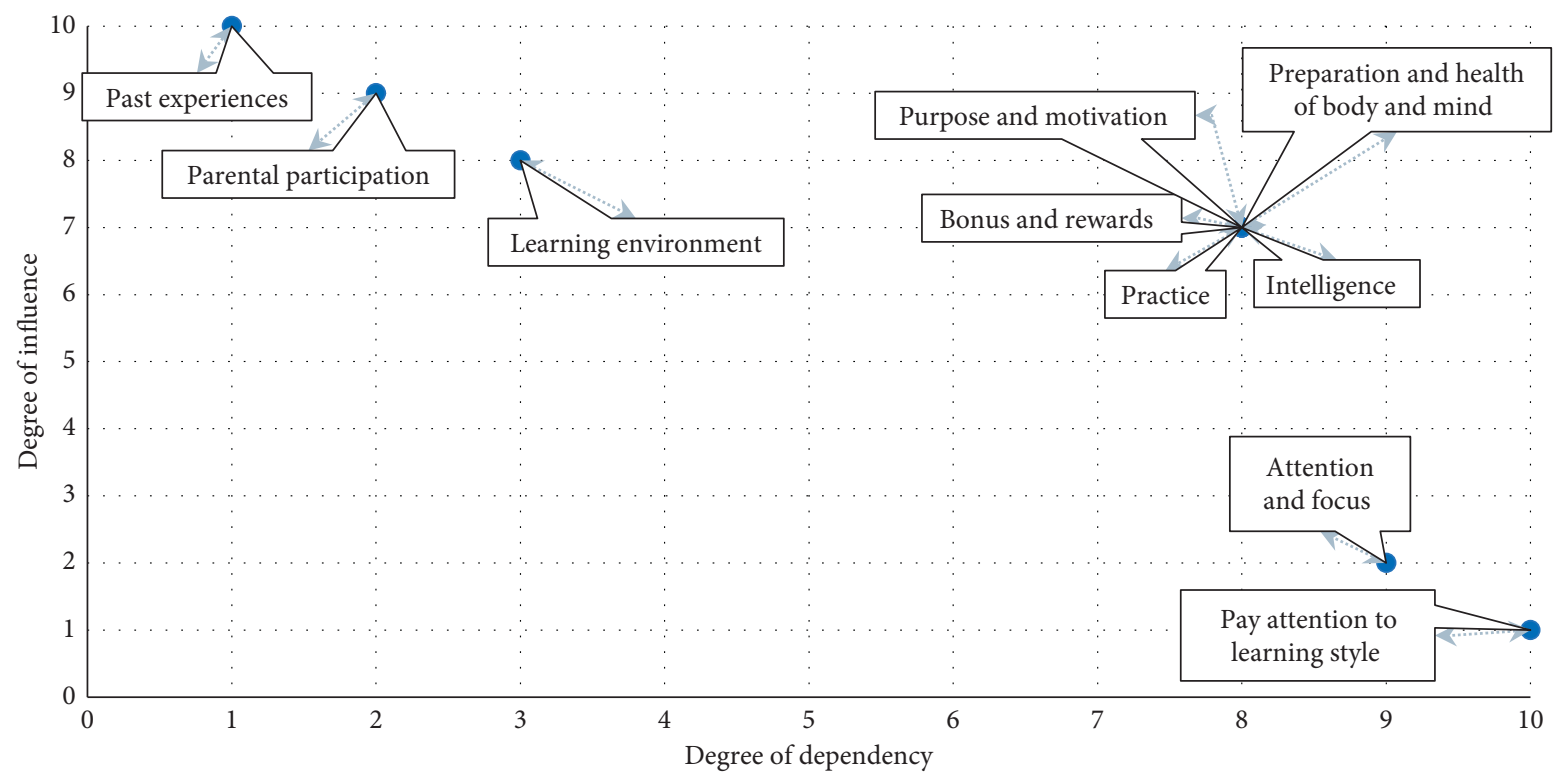

FIGURE 13: MICMAC diagram of effective criteria of the child's learning process in the ISM model.

TAвLE 2: Weight and priority of effective criteria extracted in the child learning process based on the AHP technique.

\begin{tabular}{lcc}
\hline Priority & Criterion name & Criterion weight \\
\hline 1 & Purpose and motivation & $0 / 22504$ \\
2 & Practice & $0 / 11879$ \\
3 & Preparation and health of body and mind & $0 / 10942$ \\
4 & Attention and focus & $0 / 10274$ \\
5 & Intelligence & $0 / 08824$ \\
6 & Parental participation & $0 / 08151$ \\
7 & Learning environment & $0 / 07514$ \\
8 & Pay attention to learning style & $0 / 07282$ \\
9 & Past experiences & $0 / 07093$ \\
10 & Bonus and rewards & $0 / 05537$ \\
\hline
\end{tabular}

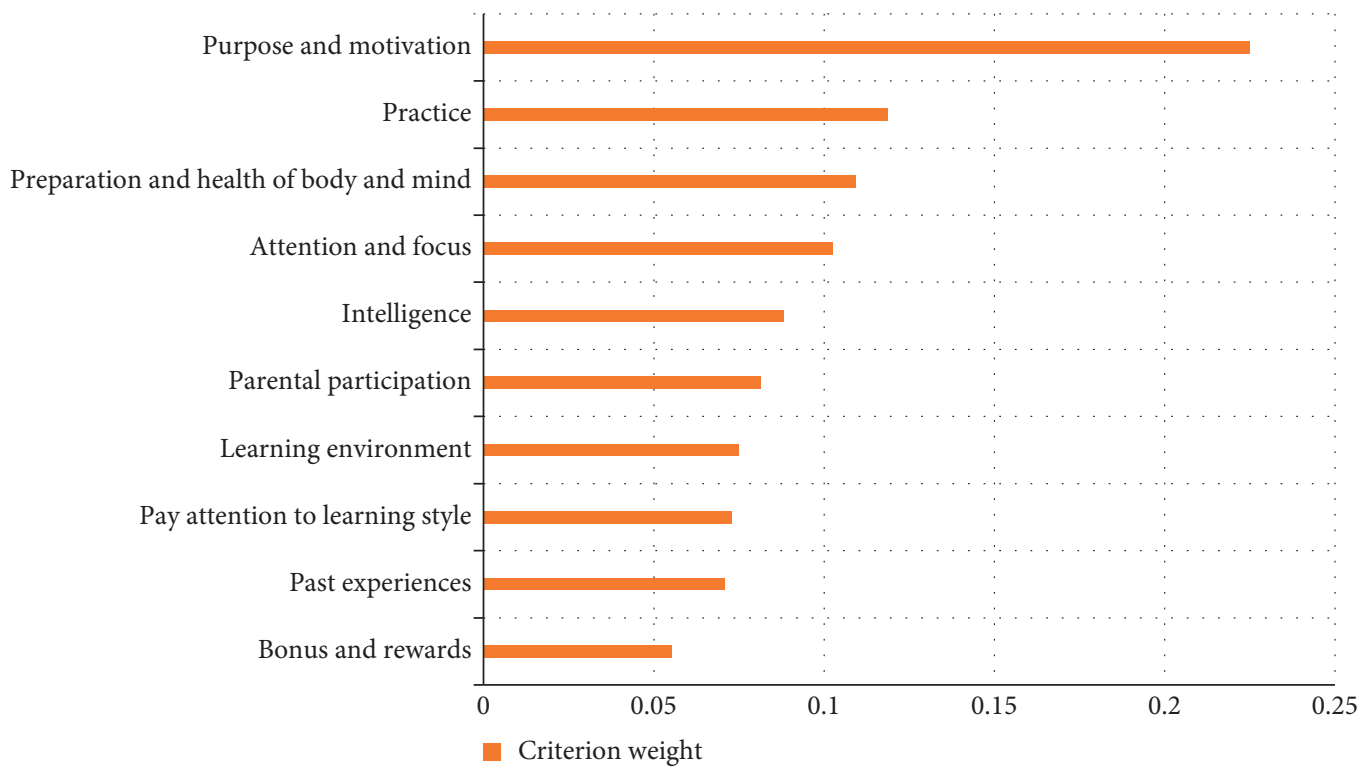

FIGURE 14: Weight diagram of effective criteria extracted in the child learning process based on the AHP technique. 
sent to the caregiver. Keywords can be entered into the SDI system in two ways:

(1) Manually: in this case, educators alert the child's status to his/her parents, and they select the keywords and enter them into the SDI system according to the child's status.

(2) Automatically using IoT: in this case, the objects are interconnected and do not require human intervention. This way the labels and categories where the child is placed are converted into keywords and sent to the SDI system. The SDI system also sends matching documents to child caregivers after matching keywords with documents.

5.4.8. Parents and Their Impact on Children's Education and Performance. As stated in the proposed educational method and previous sections, the diagnostic status of each child and the most up-to-date strategies and content are sent to the child's parents. Also, in order to communicate properly, parents should pay attention to the following points:

(1) Parents should have a friendly relationship with their children so that they can implement the proposed solutions with high efficiency.

(2) In order to improve the status of their child, parents should keep the family environment away from any conflicts and tensions.

(3) Parents should interact with mentors while using the solutions provided and use their advice.

(4) Parents should be careful not to go to extremes in applying the proposed solutions. The child's activities during the week should be divided and given a specific time for fun, watching TV, and doing homework.

(5) Parents should try to reduce children's fear of failing to do what is suggested.

(6) In the modern world, parents are involved in many different things, and they may not have enough time to raise their children. It is important to note that parents should not only pay attention to the duration but also to the quality. Parents can make the most of their time despite their small presence. That is, the quality of communication is important.

5.5. Evaluation Phase. In this section, the methods of evaluating children's educational progress after the proposed educational method and strategies are discussed. For evaluation, the game is repeated, and the multilayer networks of communication and education are extracted. Two local and general measures can then be used to measure children's educational progress as described below.

5.5.1. Local Measures. These measures are used to evaluate the educational progress of each child separately. Suggested measures are as follows:
(1) Comparison of the input degree of each node (child) from the initial communication network with the input degree of that node from the secondary communication network.

(2) Comparison of the output degree of each node (child) from the initial communication network with the output degree of that node from the secondary communication network.

(3) Comparison of the input degree of each node (child) from the initial education network with the input degree of that node from the secondary education network.

(4) Comparison of the output degree of each node (child) from the initial education network with the output degree of that node from the secondary education network.

(5) Comparison of the distance of input degrees of each node (child) from the initial communication network with the complete communication network.

(6) Comparison of the distance of output degrees of each node (child) from the initial communication network with the complete communication network.

(7) Comparison of the distance of input degrees of each node (child) from the initial education network with the complete education network.

(8) Comparison of the distance of output degrees of each node (child) from the initial education network with the complete education network.

5.5.2. General Measures. This measure is used to evaluate the level of educational improvement of all children. Suggested measures are as follows:

(1) Comparison of the average degrees of the initial communication network with the average degrees of the secondary communication network.

(2) Comparison of the average degrees of the initial education network with the average degrees of the secondary education network.

(3) Comparison of the distance between the average degrees of the initial communication network with the average degrees of the complete network.

(4) Comparison of the distance between the average degrees of the initial education network with the average degrees of the complete network.

5.6. Diagram of the Proposed Educational Method. In Figure 15 , the diagram of the proposed method is plotted. Rectangles are inputs and outputs, and processes are written in front of them.

\section{Implementation and Testing of the Proposed Educational Method}

This section tests the proposed educational method in two English language kindergartens. The number of children 


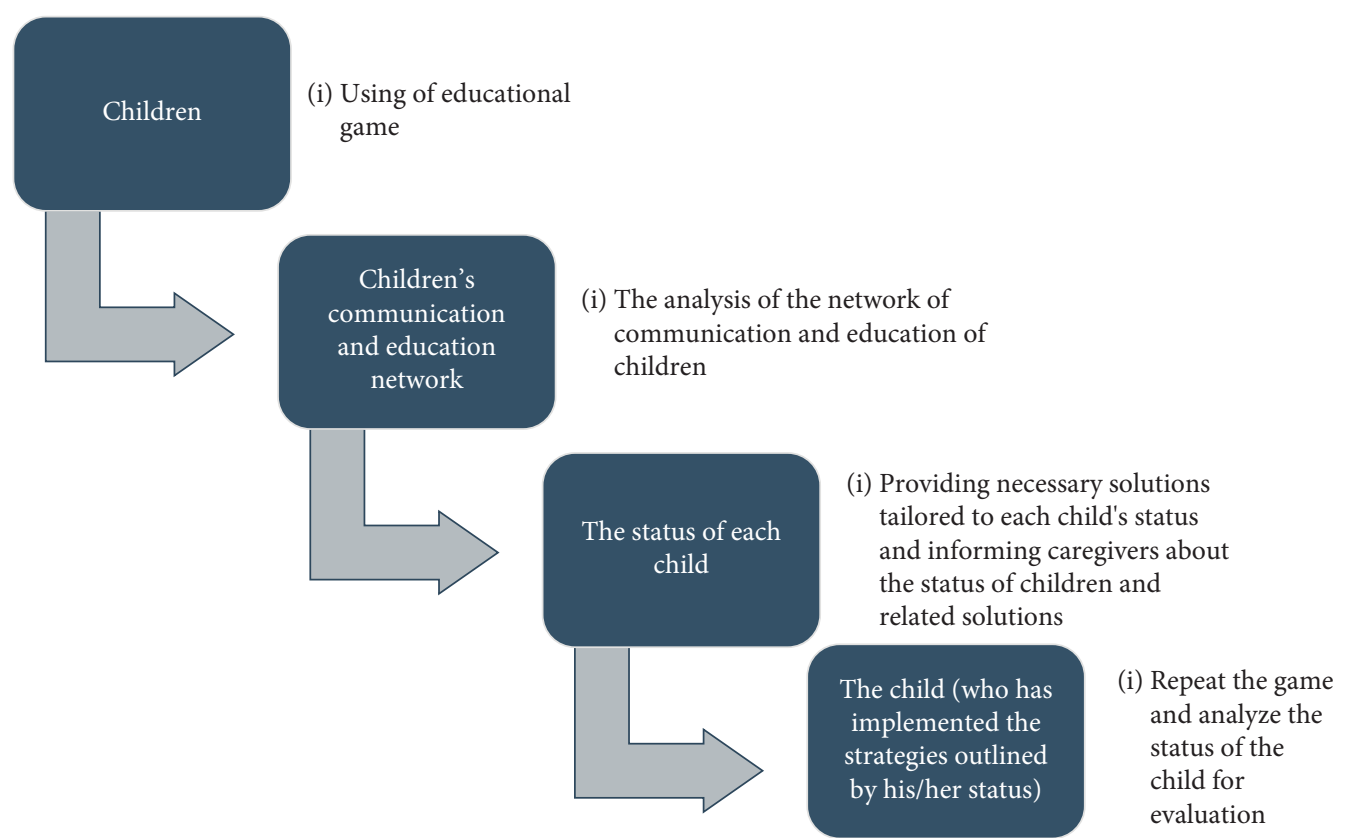

Figure 15: Diagram of the proposed educational method.

tested in the first English language kindergarten was 3 $(n=3)$, and the number of children tested in the second English language kindergarten was $6(n=6)$. In total, the proposed educational method has been tested on 9 children. According to reference [48], this number has been approved. Also, all necessary permissions have been obtained from parents and the responsible person of the kindergarten. The children ranged in age from 8 to 10 years. In consultation with the instructor, two topics were new to the selected children for the experiment. Topics were planets and fruits.

According to the game-based learning, the educational game was designed. The educational game was such that each child was taught an English word by the instructor and assigned to the child $(m=1)$. The children had to refer to each other and teach their English word to other children. Children received points based on words they had successfully taught or learned. Also, in order to identify the children's communication network, another card was considered as an identification card. Figure 16 shows the identification and educational cards.

IoT was used to extract the communication and education networks. The identification and educational cards were equipped with a QR code for each child. Each child scanned the QR code of the identification card when referring to other children to teach English words. Also, if he was able to successfully teach his word to another child, he would scan the QR code of that child's educational card. Figure 17 shows an example of a QR code scan of the cards.

Figure 18 shows part of the educational play between children in the first and second English language kindergartens.

From scanning QR codes and identification and educational cards, communication and education networks were formed. Figure 19 shows an example of a system output matrix related to the network resulting from the educational game.

Complex networks and centrality measures were used to analyze the communication and education networks from the educational game. The child's status was determined based on the number of communications each child had with the other children and the number of words the child was able to teach successfully.

MADM techniques including ISM and AHP which were mentioned in the proposed educational method were used to provide solutions based on the status of each child. At the end, the educational game was performed again after presenting the solutions. The communication and education networks obtained from the first and second experiments were compared in order to evaluate the improvement of the children's educational status.

\section{Results}

In this section, the improvements of the proposed educational method are discussed. Figure 20(a) shows the communication network from the results of the first experiment, and Figure 20(b) shows the education network from the results of the first experiment in the first English language kindergarten.

Because the number of nodes in the communication network is 3, each node can have a maximum of 2 input links and 2 output links. According to the proposed educational method, nodes with less than half of the total number of input and output links are designated as low-communication children for teaching and learning. According to Figure 20(a), a child with low communication was not identified. In the education network, nodes that have at least half the maximum number of input links can be identified as weak learners. According to Figure 20(b), child 1 is identified as a weak 


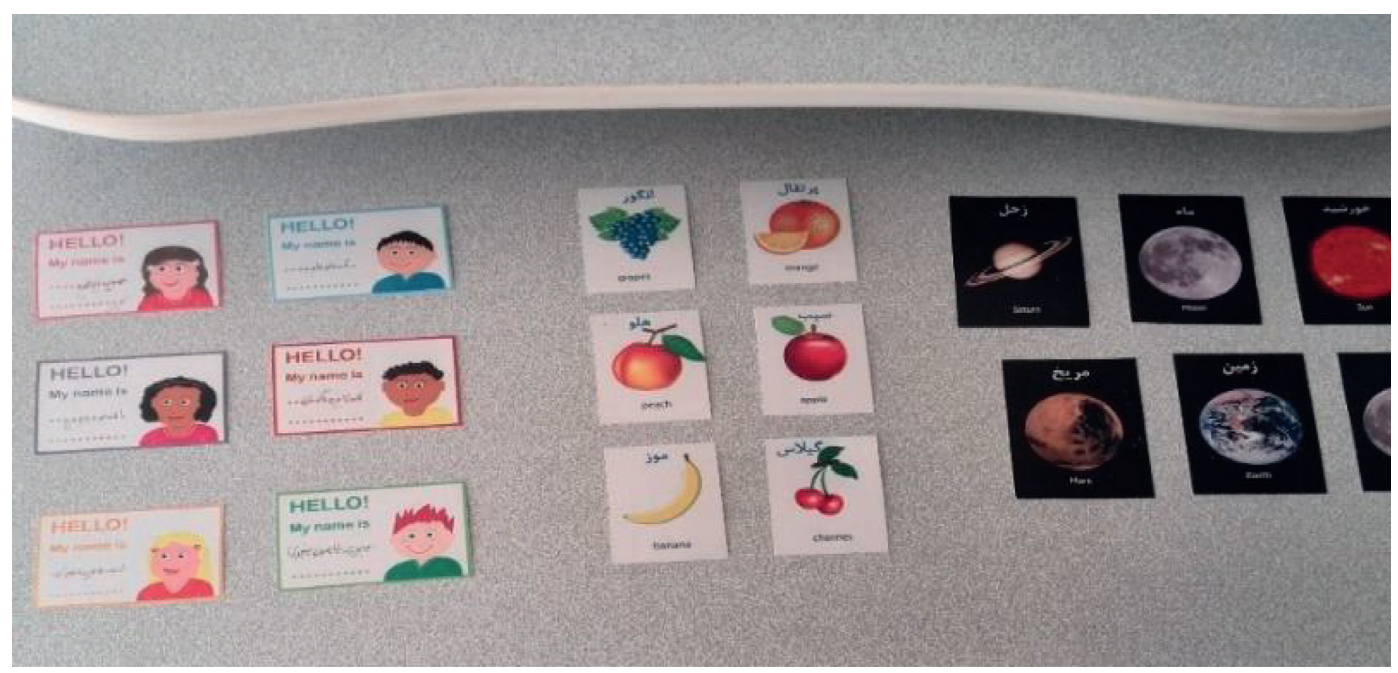

FIgURE 16: Identification and educational cards for testing.

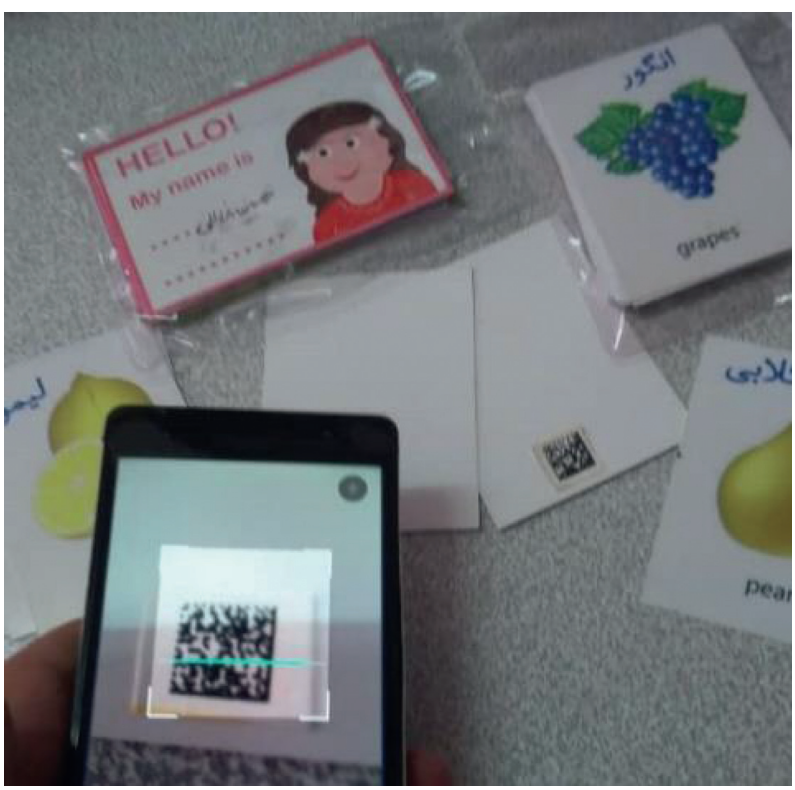

FIgURE 17: Example of scanning QR codes of cards.

learner (due to the number of input links less than 1). Also, in the education network, nodes with less than half the maximum possible number of output links are designated as a weak educator. According to Figure 20(b), child 2 was identified as a weak educator (due to the number of output links less than 1).

After analyzing the communication network and the education network obtained from the first experiment and using the solutions, the second experiment was performed with the second topic. Figure 21(a) shows the communication network from the results of the second experiment, and Figure 21(b) shows the education network from the results of the second experiment in the first English language kindergarten.

Table 3 compares the performance of each child and their evaluation (according to the local and general evaluation measures expressed in the previous sections) based on the results of the first and second experiments.

Figure 22 shows the child performance diagrams in the education network from the first and second experiments in the first English language kindergarten.

As can be seen in Figure 22, child learning rate 1 and child teaching rate 2 increased in the second experiment compared to the first experiment.

The proposed educational method was also tested on another English language kindergarten with 6 children. Figure 23(a) shows the communication network from the results of the first experiment, and Figure 23(b) shows the education network from the results of the first experiment.

Then, these networks are analyzed, and the solutions described are discussed. For example, according to Figure 23(a), child 1 had low communication with other 

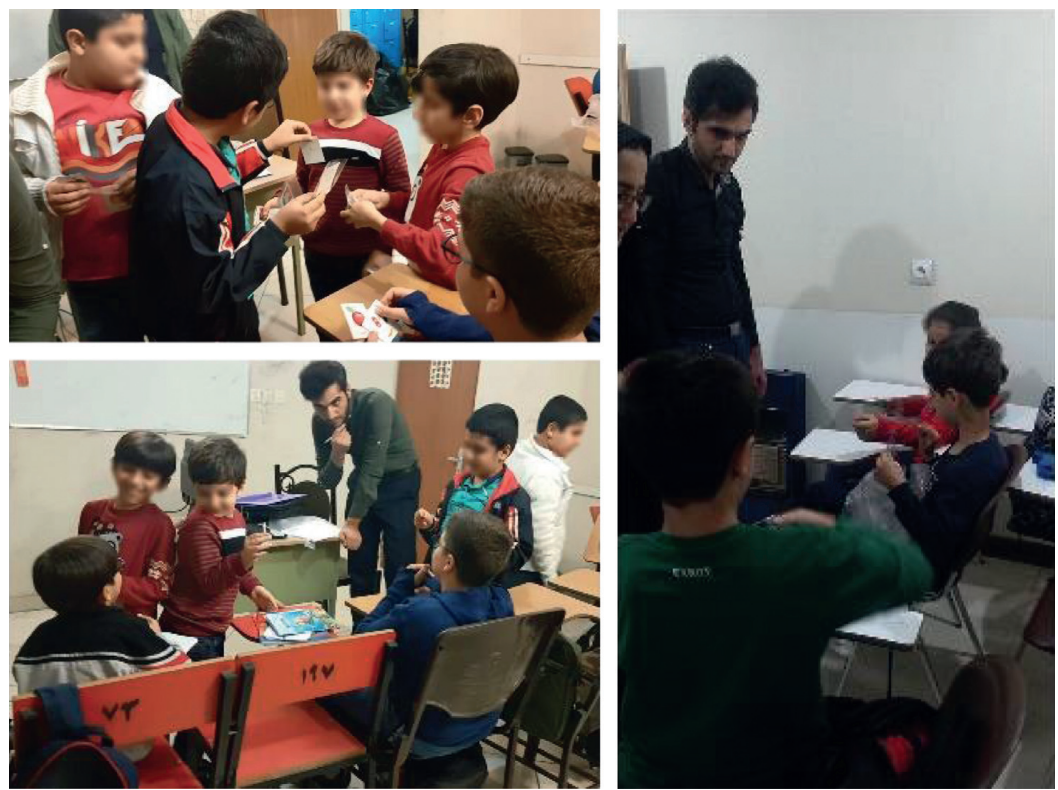

FIGURE 18: Part of the educational game between children in the first and second English language kindergartens.

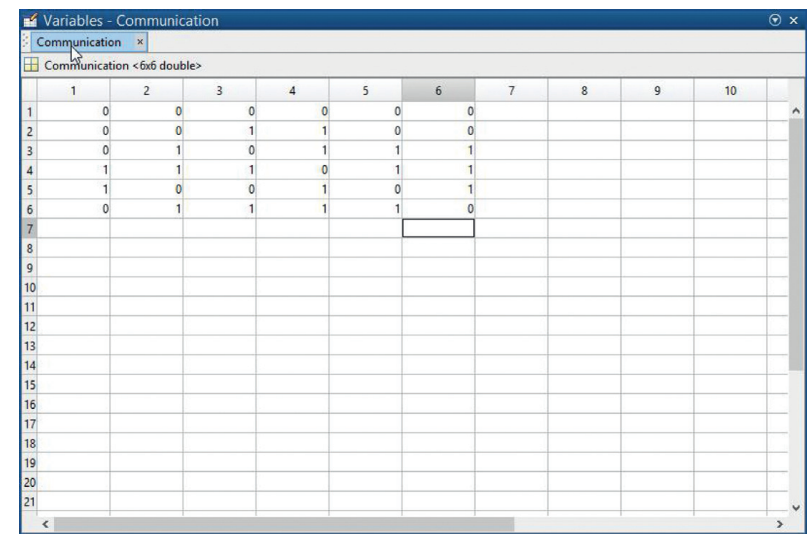

Figure 19: An example of a network output matrix from the educational game.

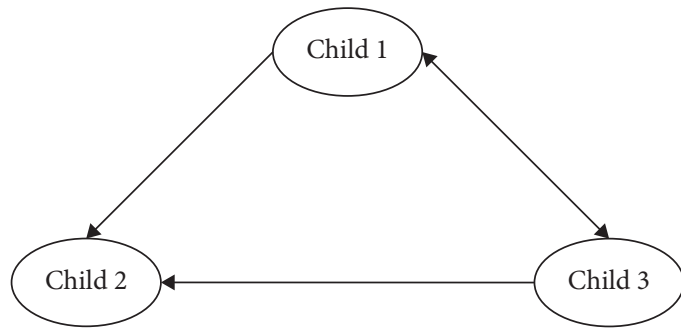

(a)

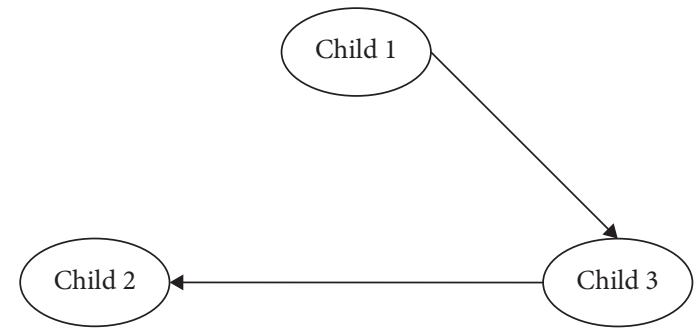

(b)

Figure 20: (a) Communication network from experiment 1; (b) education network from experiment 1.

children (he did not go to teach other children and only two children referred him for teaching) resulting in low education for this child. This child was placed in the category of low input and output communication and tried to improve his communication skills. Child 4 has referred to all children to teach, and all children except child 1 have turned to him to teach. This child was placed in the high input and output communication category and was identified as a charismatic child. But this child, according to Figure 23(b), has not been very successful in the teaching and learning process, despite having high referrals. Therefore, due to the charisma of this child, it was tried to reinforce his teaching and learning skills 


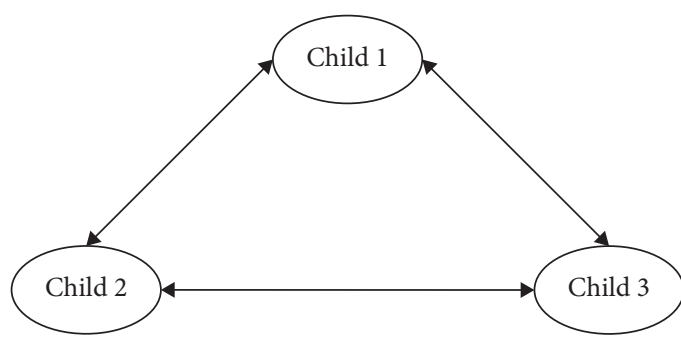

(a)

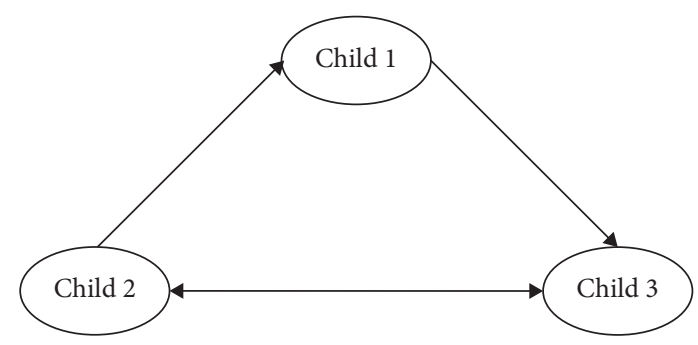

(b)

FIGURE 21: (a) Communication network from experiment 2; (b) education network from experiment 2.

TABLE 3: Children's performance in the first and second experiments in the first English language kindergarten using local and general measures.

\begin{tabular}{|c|c|c|c|c|}
\hline Experiment number & Type of measure & Child & Number of words learned & Number of words taught \\
\hline \multirow{4}{*}{ Experiment 1} & \multirow{3}{*}{ Local measure } & Child 1 & 0 & 1 \\
\hline & & Child 2 & 1 & 0 \\
\hline & & Child 3 & 1 & 1 \\
\hline & General measure & Average for all children & 0.66 & 0.66 \\
\hline \multirow{4}{*}{ Experiment 2} & \multirow{3}{*}{ Local measure } & Child 1 & 1 & 1 \\
\hline & & Child 2 & 1 & 2 \\
\hline & & Child 3 & 2 & 1 \\
\hline & General measure & Average for all children & 1.33 & 1.33 \\
\hline
\end{tabular}

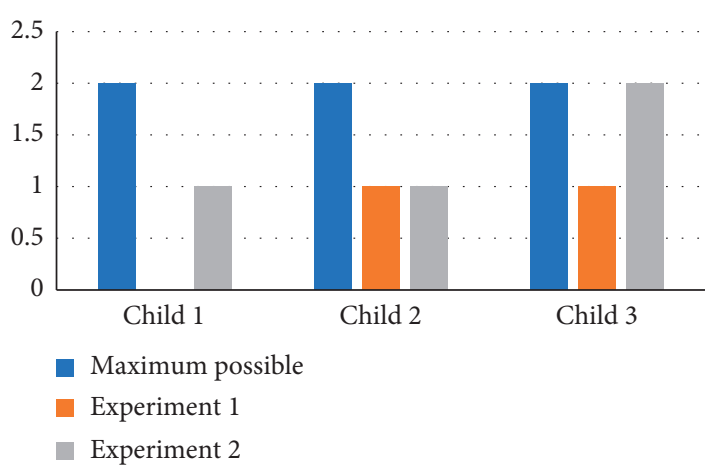

(a)

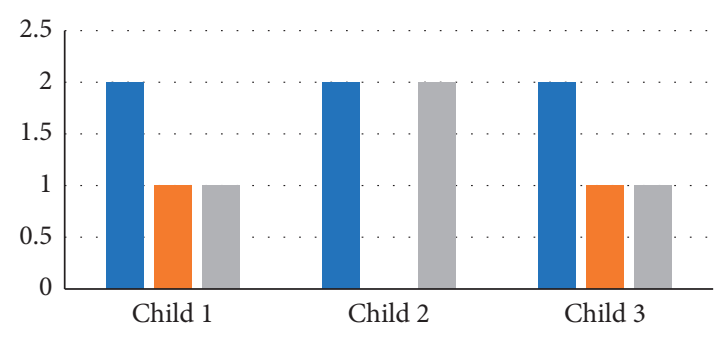

- Maximum possible Experiment 1 Experiment 2

(b)

FIGURE 22: Child performance diagrams in the education network from experiments 1 and 2 in the first English language kindergarten. (a) Number of words learned. (b) Number of words taught.

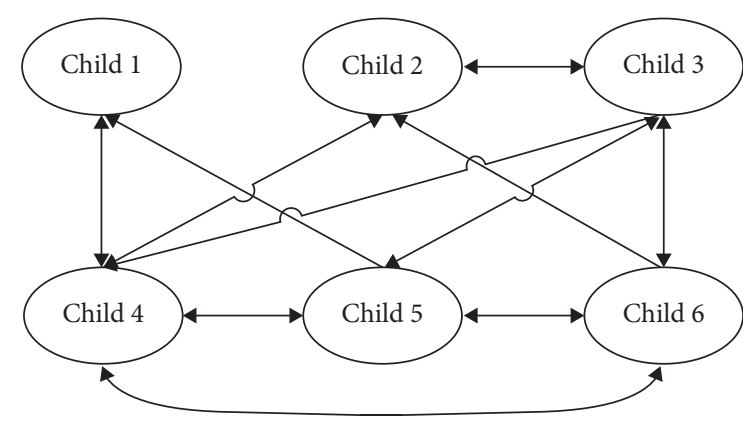

(a)

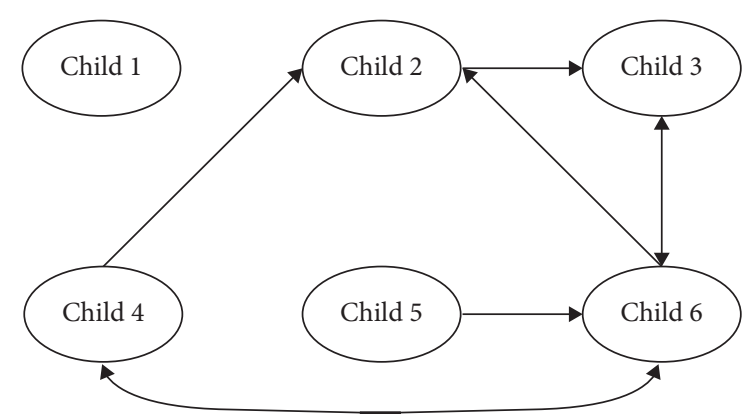

(b)

FIgURE 23: (a) Communication network derived from the first experiment; (b) education network derived from the first experiment. 


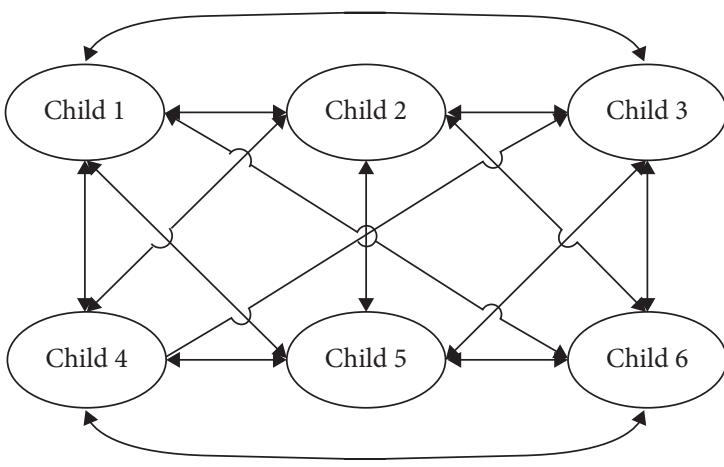

(a)

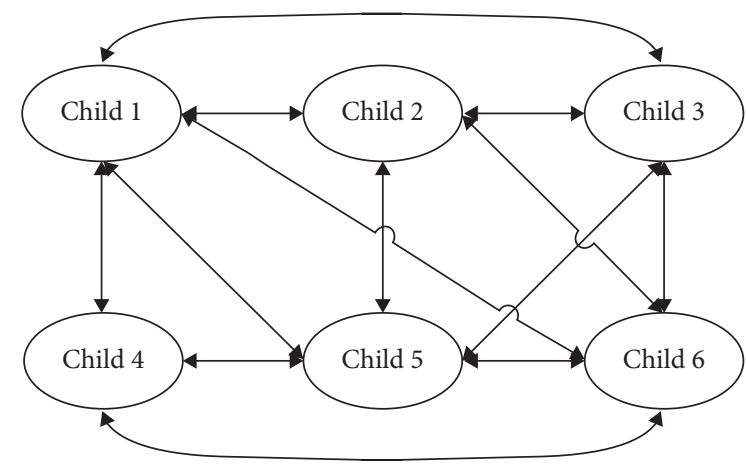

(b)

Figure 24: (a) Communication network derived from the second experiment; (b) education network derived from the second experiment.

TABLE 4: Evaluation of children's performance in experiments 1 and 2 in the second English language kindergarten using local and general measures.

\begin{tabular}{|c|c|c|c|c|c|c|}
\hline $\begin{array}{l}\text { Experiment } \\
\text { number }\end{array}$ & $\begin{array}{l}\text { Type of } \\
\text { measure }\end{array}$ & Child & $\begin{array}{l}\text { Number of input } \\
\text { communications }\end{array}$ & $\begin{array}{l}\text { Number of output } \\
\text { communications }\end{array}$ & $\begin{array}{c}\text { Number of } \\
\text { words learned }\end{array}$ & $\begin{array}{c}\text { Number of } \\
\text { words taught }\end{array}$ \\
\hline \multirow{7}{*}{ Experiment 1} & \multirow{6}{*}{$\begin{array}{c}\text { Local } \\
\text { measure }\end{array}$} & Child 1 & 2 & 0 & 0 & 0 \\
\hline & & Child 2 & 3 & 2 & 2 & 1 \\
\hline & & Child 3 & 3 & 4 & 2 & 1 \\
\hline & & Child 4 & 4 & 5 & 1 & 2 \\
\hline & & Child 5 & 3 & 3 & 0 & 1 \\
\hline & & Child 6 & 3 & 4 & 3 & 3 \\
\hline & $\begin{array}{l}\text { General } \\
\text { measure }\end{array}$ & $\begin{array}{c}\text { Average for all } \\
\text { children }\end{array}$ & 3 & 3 & 1.33 & 1.33 \\
\hline \multirow{7}{*}{ Experiment 2} & \multirow{6}{*}{$\begin{array}{c}\text { Local } \\
\text { measure }\end{array}$} & Child 1 & 5 & 5 & 2 & 5 \\
\hline & & Child 2 & 5 & 5 & 4 & 1 \\
\hline & & Child 3 & 5 & 5 & 4 & 1 \\
\hline & & Child 4 & 5 & 5 & 2 & 3 \\
\hline & & Child 5 & 5 & 5 & 2 & 4 \\
\hline & & Child 6 & 5 & 5 & 3 & 3 \\
\hline & $\begin{array}{l}\text { General } \\
\text { measure }\end{array}$ & $\begin{array}{l}\text { Average for all } \\
\text { children }\end{array}$ & 5 & 5 & 2.83 & 2.83 \\
\hline
\end{tabular}

so that his referrals to others and those referring to him could be effective in teaching more vocabulary. Also, according to Figure 23(b), child 6 had better learning. We tried to identify the criteria that helped him in the learning process and reinforce it in other children.

After analyzing the communication and education networks obtained from the first experiment and applying the strategies, the second experiment was conducted with the second subject. Figure 24(a) shows the communication network from the results of the second experiment, and Figure 24(b) shows the education network from the results of the second experiment.

Table 4 compares the performance of each child and their evaluation based on the results of the first and second experiments.

Figure 25 shows the results of the child performance diagrams in the communication and education networks obtained from the first and second experiments.

As can be seen from Table 4 and Figure 25, we can observe a good improvement of children in the teaching and learning process. Also, as can be seen in Table 3, in the implementation of the proposed educational method in the first English language kindergarten, the rate of improvement of education and learning of children according to the general measure has almost doubled (from 0.66 to 1.33), which is proportional to the doubling of the number of children tested in the implementation of the proposed educational method in the second English language kindergarten, which has also been maintained (from 1.33 to 2.83), which can be seen in Table 4 . Therefore, we can expect the compatibility of the results of the proposed educational method for different populations. Table 5 shows the percentage of children's learning in the first and second experiments in the first and second English language kindergartens.

Other advantages of the proposed educational method include the following:

(1) Games are attractive for children, so using games to teach children can be very effective and useful. It is difficult for the teacher to control the children, 


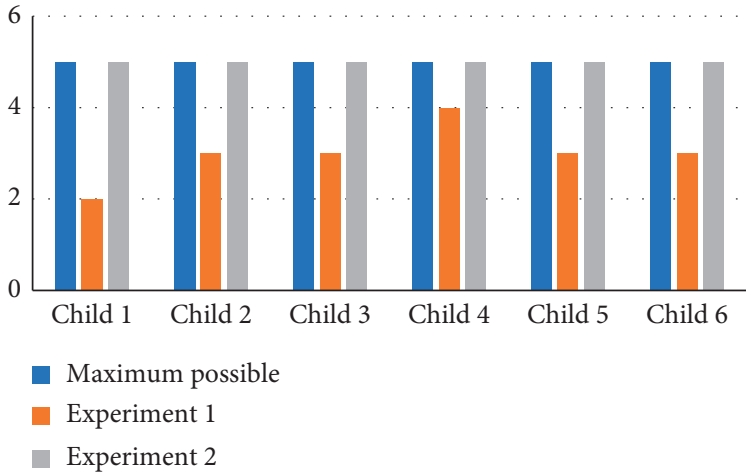

(a)

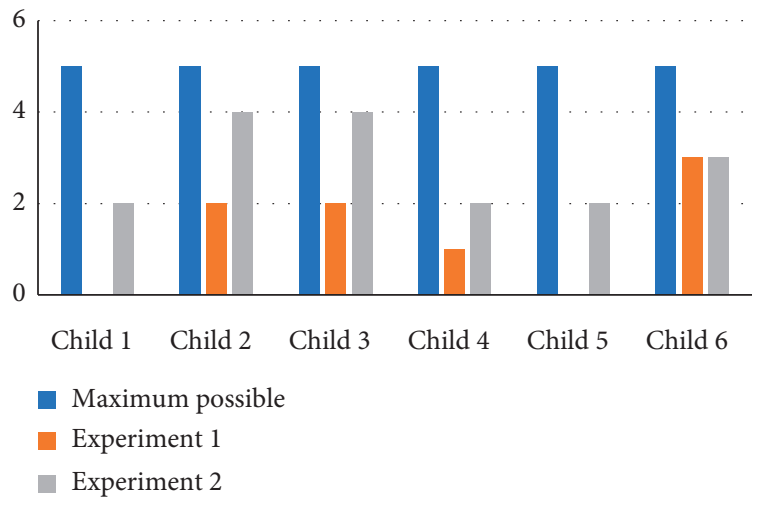

(c)

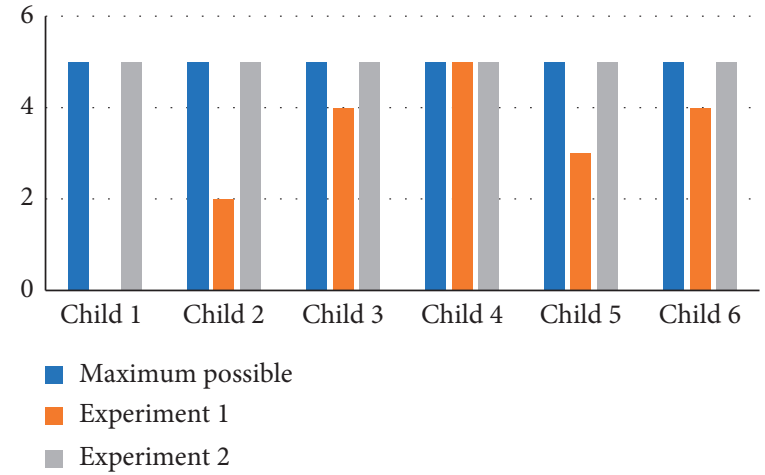

(b)

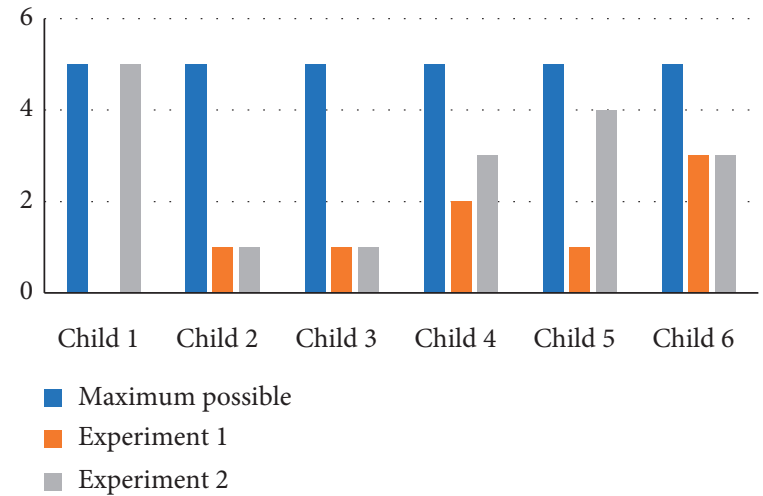

(d)

Figure 25: Child performance diagrams in the communication and education networks from experiments 1 and 2 in the second English language kindergarten. (a) Number of input communications. (b) Number of output communications. (c) Number of words learned. (d) Number of words taught.

Table 5: Percentage of children's learning in the first and second experiments in the first and second English language kindergartens.

\begin{tabular}{lcc}
\hline Study & Experiment number & Vocabulary gains (\%) \\
\hline \multirow{2}{*}{ Proposed method, English language kindergarten 1 } & Experiment 1 & 33 \\
\hline \multirow{2}{*}{ Proposed method, English language kindergarten 2 } & Experiment 2 & 66.5 \\
\hline
\end{tabular}

TABle 6: Related work summaries based on researchers' name, year of publication, brief description, and results.

\begin{tabular}{llll}
\hline Name of researchers & $\begin{array}{c}\text { Year of } \\
\text { publication }\end{array}$ & Brief description & Results \\
\hline
\end{tabular}

The results show that both modes of play create positive emotions such as enthusiasm, pleasure,

This study evaluates the use of mobile-based multiplayer games for primary school children. In this research, two applications of this type of

López-Faican

2020 games are considered: (1) competition against the common game; (2) game using mobile technology

that creates a geographical scenario with unlimited physical space. and curiosity in children. It has been observed that joint play has a greater impact on emotional affection, social interaction, and interest. In addition, it was observed that the quality of communication in the participatory mode is good in terms of various factors such as maintaining mutual understanding, dialogue management, information collection, reaching consensus, time management, and interaction. 
TABle 6: Continued.

\begin{tabular}{|c|c|c|c|}
\hline Name of researchers & $\begin{array}{c}\text { Year of } \\
\text { publication }\end{array}$ & Brief description & Results \\
\hline Abdi & 2019 & $\begin{array}{l}\text { This study examines the creation of an affordable, } \\
\text { sustainable, and safe educational toy for } \\
\text { prekindergarten children between the ages of } 4 \\
\text { and } 5 \text { for teaching English language as a second } \\
\text { language in developing countries. }\end{array}$ & $\begin{array}{l}\text { The findings of this study show that the } \\
\text { developed toy can be suitable for use as an } \\
\text { educational toy for prekindergarten children to } \\
\text { teach English language as a second language. }\end{array}$ \\
\hline Sadiq & 2019 & $\begin{array}{l}\text { Creating an educational application that can be } \\
\text { run on a mobile phone based on the principles of } \\
\text { user interface design using voice recognition } \\
\text { engines to convert text to speech, which will help } \\
\text { children learn English language. }\end{array}$ & $\begin{array}{l}\text { The opinions of a group of children showed that } \\
\text { they were happy to use the developed } \\
\text { application. Furthermore, it can be said that the } \\
\text { mobile application achieved its aims in teaching } \\
\text { English as a foreign language and that the } \\
\text { application is suitable as an educational item. } \\
\text { Results show that diegetic feedback led to the }\end{array}$ \\
\hline $\mathrm{Li}$ & 2019 & $\begin{array}{l}\text { In this paper, an exploratory experiment is } \\
\text { reported to examine the impact of different } \\
\text { interaction techniques and different feedback } \\
\text { mechanisms in mathematics education for } \\
\text { children. }\end{array}$ & $\begin{array}{l}\text { game being considered significantly more } \\
\text { enjoyable, as well as inducing greater feelings of } \\
\text { competence and autonomy; screen-touch } \\
\text { interaction versus tangible interaction did not } \\
\text { change motivation directly nor did find } \\
\text { interaction effects between the presentation and } \\
\text { interaction modes. }\end{array}$ \\
\hline Zhamanov & 2018 & $\begin{array}{l}\text { The study looked at the combination of IoT and } \\
\text { gaming and examined a classroom equipped with } \\
\text { modern items such as IoT and gaming. }\end{array}$ & $\begin{array}{l}\text { The modern classroom method is better than the } \\
\text { traditional classroom with a difference of } \\
\text { approximately } 20 \% \text { increase in average } \\
\text { attendance, lab work, tests, midterm exams, and } \\
\text { final exams. }\end{array}$ \\
\hline
\end{tabular}

Spyrou

Tangworakitthaworn

de la Guía

Safar

Uzelac

Manches

de la Guía In this research, the use of IoT in the game is
discussed. A learning goal is set, and the path to that goal is divided into several tasks called learning atoms, which are designed for each game.

In this research, a game-based learning system for plant monitoring based on IoT technology has been designed.

It discusses the impact of using IoT to help teachers strengthen social interactions and classroom interactions.

This experimental research study scrutinized the effectiveness of using augmented reality applications as a teaching and learning item when instructing kindergarten children in the English alphabet in the State of Kuwait.

The parameters that affect the students' focus during the lecture are extracted using IoT.

Three questions have been designed about the IoT and children. This study examines these questions according to the IoT.

An e-book for children is presented. Doll characters have been used to increase children's motivation to read books.

First, an overview of extensive research on the impact of technology on learning to determine the rationale for the value of this information is provided. The next section examines evidence from research analysis of the impact of digital technology. The other part looks at the process of using digital technology and learning in the UK and the international world to provide more context for the necessary recommendations.

\section{Increasing learning motivation}

Increasing the motivation to learn and care for plants

It enables teachers to gain a deeper insight into their classroom. The teacher can interact with the system and students in real time. Based on student behavior, the teacher can immediately send a message to control, increase participation and motivation, and encourage cooperation among students.

Very strong linear correlation between children's interaction with English alphabet lesson and their scores in the English alphabet test of children using these applications.

After the experiments, 5 parameters that had a significant effect on students' concentration were finally extracted.

Digitizing everyday objects, such as toys, can influence children's attitudes, behavior, and thus educate children and affect children's daily activities.

Increasing the motivation to read books

(i) Technology sharing (in pairs or small groups) is usually more effective than individual use.

(ii) Technology can be used as a centralized intervention to improve learning.

(iii) Technology should be used as a supplement to conventional education rather than as a substitute. 
especially in games, due to their high mobility. Using the IoT technology discussed in the proposed educational method, it is possible to extract the communication network and the education network from the educational game automatically and without the need for teacher control.

(2) In traditional methods, the network of communication and education of children is not extracted and analyzed. In the proposed educational method, using the knowledge of complex networks and centrality measures, different status of children has been identified in order to strengthen their learning process. More importantly, this analysis can be done in real time while extracting networks through IoT technology, which can help the teacher identify the status of children in the shortest possible time, especially in high-node networks.

(3) In traditional methods, identifying the most up-to-date content and strategies to improve a child's diagnosed status is either not done or will take a long time. In the proposed educational method, using SDI, the teacher and parents will get the most up-to-date information and strategies to improve their child's diagnosed status in the shortest possible time. Also, in the proposed method, using SDI, it is possible to choose how to access this information (using social networks, e-mail, and mobile phone), the number of contents and documents, the author of the content, the time of publishing the content, etc., for parents and teachers which will increase the ease and efficiency that did not exist in traditional methods.

(4) In the proposed educational method, all steps from identifying the children's status, providing solutions and evaluation, are done automatically and in the shortest possible time, which will increase ease, accuracy, and efficiency, which was not possible with traditional methods.

\section{Discussion}

The results showed that the proposed educational method can improve children's communication in the educational process. By improving communication, children can help each other in the learning process. This is child-to-child education. In traditional methods, there is only instructorto-child education, and child-to-child education is not considered. The data obtained in this study showed that the proposed method has improved the education process by considering child-to-child education. Also, according to the research questions and the results of Tables 3 and 4, the proposed solutions using MADM techniques have been able to improve the educational status of children. In the proposed method, the condition of each child is diagnosed separately, and solutions are provided in accordance with the condition of each child, which is not considered in traditional methods. Also, according to the results of Table 5, the proposed educational method has been able to double the rate of children's learning, which is maintained by doubling the number of children tested. According to the purpose of the research, in the proposed educational method, the art and creativity of combining games that are attractive to children with technologies such as IoT were used to increase children's motivation and participation in the learning process and thus improve the learning process. The results confirmed the realization of this goal.

\section{Conclusion}

This paper presents a method for educating children. The proposed educational method utilized technologies and items such as SDI, complex networks and centrality measures, MADM, and games in the IoT environment. Each of these items was explained first. Then, the proposed educational method was expressed in three phases of diagnosis, improvement, and evaluation. In related works, only one of the phases is usually considered, but in the proposed educational method, all three phases are considered. In the proposed educational method, IoT was used to extract the children's communication network and education. These networks were then analyzed using centrality measures, and the children were categorized into different categories that reported their status. MADM techniques were used to provide solutions for some categories. The child's learning styles were also addressed in providing strategies. In the evaluation phase, local and general measures were defined for evaluation. The proposed educational method was tested in 2 experiments and on a total of 9 children. The results showed that the proposed educational method was able to improve children's learning. The most important reasons for this are the combination of technology in educational games in order to extract the network of communication and education of children using IoT technology, provide the best solutions using SDI, etc., and in general, to automate the steps from identifying each child's educational status to providing the most up-to-date strategies related to each child's diagnosed status.

In this study, the educational game was designed so that each child should teach the other children. It was not considered to divide the children into groups and that each group would teach the children of the other group. This restriction did not allow the use of other network measures such as betweenness centrality and page rank centrality. Considering group games and using other measures of centrality in the analysis of the resulting networks can be considered as future work.

\section{Appendix}

(1) Table of related works based on researchers' names, year of publication, brief description, and results (Table 6).

(2) The data for this paper are available at the following link: https://www.4shared.com/zip/VQm8_xWRiq/Data. html. 


\section{Data Availability}

The data for this paper are available at the following link: https://www.4shared.com/zip/VQm8_xWRiq/Data.html.

\section{Conflicts of Interest}

The authors declare that there are no conflicts of interest regarding the publication of this manuscript.

\section{References}

[1] S. Agnihotri, "The importance of early childhood education for a sustainable society: a sociological analysis," Journal of Bank Management \& Financial Strategies, vol. 2, no. 3, pp. 26-32, 2019.

[2] M. T. Merrick, K. A. Ports, D. C. Ford, T. O. Afifi, E. T. Gershoff, and A. Grogan-Kaylor, "Unpacking the impact of adverse childhood experiences on adult mental health," Child Abuse \& Neglect, vol. 69, pp. 10-19, 2017.

[3] P. N. Stearns, Childhood in World History, Routledge, Abingdon, UK, 2016.

[4] C. Magnusson and M. Nermo, "From childhood to young adulthood: the importance of self-esteem during childhood for occupational achievements among young men and women," Journal of Youth Studies, vol. 21, no. 10, pp. 1392-1410, 2018.

[5] A. Bell, R. Chetty, X. Jaravel, N. Petkova, and J. Van Reenen, "Who becomes an inventor in America? The importance of exposure to innovation," The Quarterly Journal of Economics, vol. 134 , no. 2, pp. $647-713,2018$.

[6] K. Sylva, E. Melhuish, P. Sammons, I. Siraj-Blatchford, and B. Taggart, Early Childhood Matters: Evidence from the Effective Pre-School and Primary Education Project, Routledge, Abingdon, UK, 2010.

[7] E. L. Essa, Introduction to Early Childhood Education, Cengage Learning, Boston, MA, USA, 2012.

[8] B. S. Bloom, Stability and Change in Human Characteristics, Wiley, Hoboken, NJ, USA, 1964.

[9] K. W. M. Siu and M. S. Lam, "Early childhood technology education: a sociocultural perspective," Early Childhood Education Journal, vol. 32, no. 6, pp. 353-358, 2005.

[10] N. A. Jennings, S. D. Hooker, and D. L. Linebarger, "Educational television as mediated literacy environments for preschoolers," Learning, Media and Technology, vol. 34, no. 3, pp. 229-242, 2009.

[11] S. M. Fisch and R. T. Truglio, G is for Growing: Thirty Years of Research on Children and Sesame Street, Routledge, Abingdon, UK, 2014.

[12] D. Evans, "The internet of things: how the next evolution of the internet is changing everything," 2011, http://www.cisco.com/ web/about/ac79/docs/innov/IoT_IBSG_0411FINAL.pdf.

[13] K. Ashton, "That "internet of things" thing," RFID Journal, vol. 22, 1999.

[14] G. C. Fox, S. Kamburugamuve, and R. D. Hartman, "Architecture and measured characteristics of a cloud-based internet of things," in Proceedings of the 2012 International Conference on Collaboration Technologies and Systems (CTS), IEEE, Denver, CO, USA, 2012.

[15] M. Chui, M. Löffler, and R. Roberts, "The internet of things," McKinsey Quarterly, vol. 2, pp. 1-9, 2010.

[16] J. Ritz and Z. Knaack, "Internet of things," Technology \& Engineering Teacher, vol. 76, no. 6, 2017.
[17] T. T. Mulani and S. V. Pingle, "Internet of things," International Research Journal of Multidisciplinary Studies, vol. 2, no. 3, 2016.

[18] M. Keerthana and S. Ashika Parveen, "Internet of things," International Journal of Advanced Research Methodology in Engineering and Technology, vol. 1, no. 2, 2017.

[19] J. Lin, W. Yu, N. Zhang, X. Yang, H. Zhang, and W. Zhao, "A survey on internet of things: architecture, enabling technologies, security and privacy, and applications," IEEE Internet of Things Journal, vol. 4, no. 5, pp. 1125-1142, 2017.

[20] E. de la Guía, M. D. Lozano, V. M. Penichet, and R. Nieto, "NFCBOOK: GameBook digital based on tangible user interfaces," in Proceedings of the 15th International Conference on Human Computer Interaction, Munich, Germany, Septmeber 2014.

[21] I. Soute and H. Nijmeijer, "An owl in the classroom: development of an interactive storytelling application for preschoolers," in Proceedings of the 2014 Conference on Interaction Design and Children, Aarhus, Denmark, 2014.

[22] C. D. Clark, "Therapeutic advantages of play," Play and Development: Evolutionary, Sociocultural, and Functional Perspectives, pp. 275-293, Taylor \& Francis, Abingdon, UK, 2007.

[23] J. Huizenga, W. Admiraal, S. Akkerman, and G. T. Dam, "Mobile game-based learning in secondary education: engagement, motivation and learning in a mobile city game," Journal of Computer Assisted Learning, vol. 25, no. 4, pp. 332-344, 2009.

[24] K. D. Stiller and S. Schworm, "Game-based learning of the structure and functioning of body cells in a foreign language: effects on motivation, cognitive load, and performance," Frontiers in Education, vol. 4, p. 18, 2019.

[25] A. Pho and A. Dinscore, Game-Based Learning. Tips and Trends, American Library Association, Chicago, IL, USA, 2015.

[26] L. López-Faican and J. Jaen, "Emofindar: evaluation of a mobile multiplayer augmented reality game for primary school children," Computers \& Education, vol. 149, Article ID $103814,2020$.

[27] S. Trench, "Dissemination of information," Handbook of Special Librarianship and Information Work, Aslib, London, UK, 1997.

[28] E. k. O’Neil, "Selective dissemination of information in the dynamic web environment," Master thesis, University of Verginia: Faculty of the School of Engineering and Applied Science, Charlottesville, VA, USA, 2001.

[29] J. J. Huang and K. Yoon, Multiple Attribute Decision Making: Methods and Applications, Chapman and Hall/CRC, London, UK, 2011.

[30] R. Anggrainingsih, M. Z. Umam, and H. Setiadi, "Determining e-learning success factor in higher education based on user perspective using fuzzy AHP," in Proceedings of the 2nd International Conference on Engineering and Technology for Sustainable Development, vol. 154, p. 03011, Yogyakarta, Indonesia, 2018.

[31] R. V. Donner, M. Lindner, L. Tupikina, and N. Molkenthin, "Characterizing flows by complex network methods," in $A$ Mathematical Modeling Approach from Nonlinear Dynamics to Complex Systems, pp. 197-226, Springer, Cham, Switzerland, 2019.

[32] M. E. J. Newman, "The structure of scientific collaboration networks," Proceedings of the National Academy of Sciences, vol. 98, no. 2, pp. 404-409, 2001.

[33] P. J. Carrington, J. Scott, and S. Wasserman, Models and Methods in Social Network Analysis, Cambridge University Press, Cambridge, UK, 2005. 
[34] L. Freeman, "Centrality in social networks: conceptual clarification," Social Networks, vol. 1, pp. 215-239, 1979.

[35] B. Cheng, Using social network analyses to investigate potential bias in editorial peer review in core journals of comparativel international education, Ph.D. dissertation, Brigham Young University, Provo, Utah, 2006.

[36] E. Estrada, The Structure of Complex Networks: Theory and Applications, Oxford University Press, Oxford, UK, 2012.

[37] A. S. Abdi and N. Cavus, "Developing an electronic device to teach English as a foreign language: educational toy for prekindergarten children," International Journal of Emerging Technologies in Learning (iJET), vol. 14, no. 22, pp. 29-44, 2019.

[38] S. Higgins, Z. Xiao, and M. Katsipataki, The Impact of Digital Technology on Learning: A Summary for the Education Endowment Foundation, Education Endowment Foundation and Durham University, Durham, UK, 2012.

[39] A. H. Safar, A. A. Al-Jafar, and Z. H. Al-Yousefi, "The effectiveness of using augmented reality apps in teaching the English alphabet to kindergarten children: a case study in the state of Kuwait," EURASIA Journal of Mathematics, Science and Technology Education, vol. 13, no. 2, pp. 417-440, 2016.

[40] R. B. Sadiq, N. Cavus, and D. Ibrahim, "Mobile application based on CCI standards to help children learn English as a foreign language," Interactive Learning Environments, vol. 27, pp. 1-16, 2019.

[41] A. Uzelac, N. Gligoric, and S. Krco, "A comprehensive study of parameters in physical environment that impact students' focus during lecture using internet of things," Computers in Human Behavior, vol. 53, pp. 427-434, 2015.

[42] A. Manches, P. Duncan, L. Plowman, and S. Sabeti, "Three questions about the internet of things and children," TechTrends, vol. 59, no. 1, pp. 76-83, 2015.

[43] A. Zhamanov, Z. Seong-MooYoo, Z. Sakhiyeva, and M. Zhaparov, "Implementation and evaluation of flipped classroom as IoT element into learning process of computer network education," International Journal of Information and Communication Technology Education, vol. 14, no. 2, pp. 30-47, 2018.

[44] E. Spyrou, N. Vretos, A. Pomazanskyi, S. Asteriadis, and H. C. Leligou, "Exploiting IoT technologies for personalized learning," in Proceedings of the 2018 Conference on Computational Intelligence and Games (CIG), Maastricht, Netherlands, August 2018.

[45] P. Tangworakitthaworn, V. Tengchaisri, K. Rungsuptaweekoon, and T. Samakit, "A game-based learning system for plant monitoring based on IoT technology," in Proceedings of the 15th International Joint Conference on Computer Science and Software Engineering (JCSSE), Nakhon Pathom, Thailand, July 2018.

[46] J. Li, E. D. van der Spek, J. Hu, and L. Feijs, “Turning your book into a game: improving motivation through tangible interaction and diegetic feedback in an AR mathematics game for children," in Proceedings of the Annual Symposium on Computer-Human Interaction in Play, pp. 73-85, Barcelona, Spain, 2019.

[47] E. de la Guía, V. López, T. Olivares, and L. Orozco, Using Internet of Things to Support Teachers to Enhance Social and Classroom Interactions, Albacete Research Institute of Informatics (I3A), Albacete, Spain, 2018.

[48] M. Brysbaert, "How many participants do we have to include in properly powered experiments? A tutorial of power analysis with reference tables," Journal of Cognition, vol. 2, no. 1, 2019. 